\title{
Management of oxidative stress and other pathologies in Alzheimer's disease
}

\author{
Miriama Simunkova ${ }^{1} \cdot$ Saleh H. Alwasel${ }^{2} \cdot$ Ibrahim M. Alhazza ${ }^{2} \cdot$ Klaudia Jomova $^{3} \cdot$ Vojtech Kollar $^{4} \cdot$ Miroslav Rusko $^{5}$. \\ Marian Valko ${ }^{1,2}$ [D
}

Received: 27 June 2019 / Accepted: 14 August 2019 / Published online: 22 August 2019

(c) The Author(s) 2019

\begin{abstract}
Alzheimer's disease (AD) is a multifactorial neurodegenerative disorder, characterized by the formation, aggregation and accumulation of amyloid beta, perturbed metal (copper, iron and zinc) homeostasis, metal-induced oxidative stress, neuroinflammation, aberrant activity of acetylcholinesterase (AChE) and other pathologies. The aim of this review is to discuss the current therapies based on the "combination-drugs-multitargets" strategy to target multiple pathologies to block the progression of pathogenesis of AD. In addition to cholinergic and amyloid targets, a significant effort is focused on targeting the metal-induced oxidative stress component of the disease. The main focus of research is based on modifications of existing drugs with specific biological activity. Tacrine was the first AChE inhibitor to be introduced into clinical practice and has been frequently used for the design of multitarget-directed ligands. A number of hybrid compounds containing tacrine and structural moieties derived from natural sources such as flavonoids [quercetin, rutin, coumarin, gallamine, resveratrol, scutellarin, anisidine, hesperetin, (-)-epicatechin] and other molecules (melatonin, trolox) have also been applied to function as multitarget-directed ligands. Most of these hybrids are potent inhibitors of AChE and butyrylcholinesterase and also of amyloid-beta aggregation. In addition, the antioxidant functionality, represented by coumarins, melatonin and other antioxidant molecules reduces the level of oxidative stress via ROS-scavenging mechanisms, as well as via chelation of redox-active $\mathrm{Cu}$ and $\mathrm{Fe}$, thus suppressing the formation of ROS via the Fenton reaction. Various medicinal plants are under investigation for their ability to ameliorate symptoms of AD. The therapeutic potency of huperzine A and B, ginseng, curcumin and other compounds is manifested predominantly by the inhibitory action toward $\mathrm{AChE}$, antioxidant or radical-scavenging and redox metal-chelating activity, inhibition of amyloid-beta aggregation and tau-protein hyperphosphorylation and antiinflammatory activity. Flavonoids not only function as antioxidants and metal-chelating agents, but also interact with protein kinase and lipid kinase signaling pathways, and others involving mitogen-activated protein kinase, NF-kappaB and tyrosine kinase. Among the most promising group of substances with potential activity against AD are the flavonoids, including myricetin, morin, rutin, quercetin, fisetin, kaempferol, apigenin and glycitein, which have been shown, in vitro, to possess antiamyloidogenic and fibril-destabilization activity, as well as being able to act as metal chelators and to suppressing oxidative stress. In terms of the clinical use of multifunctional hybrids, herbal drugs or flavonoids against $\mathrm{AD}$, some remaining challenges are to establish the ideal dose to develop effective formulations to preserve bioavailability and to determine the stage when they should be administered. If the onset of the disease could be delayed by a decade, the number of AD victims would be significantly reduced.
\end{abstract}

Keywords Alzheimer's disease $\cdot$ Metals $\cdot$ Oxidative stress $\cdot$ Redox imbalance $\cdot$ Amyloid beta $\cdot$ Flavonoids $\cdot$ Multifunctional drugs

\section{Major hallmarks of Alzheimer's disease}

Marian Valko

marian.valko@stuba.sk

Extended author information available on the last page of the article
Alzheimer's disease (AD) is one of the most common neurodegenerative disorders and is characterized by a variety of symptoms such as loss of memory, decline of cognitive functions, abnormal behavior and psychiatric problems. AD 
is multifactorial in nature with an unknown etiology that is characterized by several pathological manifestations, including abnormal beta-amyloid (A $\beta$ ) accumulation, death of cholinergic neurons, microtubule $\tau$ protein aggregation, metal dyshomeostasis of copper, iron and zinc, metal-induced oxidative stress and other aspects (Jalili-Baleh et al. 2018).

Particular regions of the brain in AD patients display an abundance of two abnormal protein structures, amyloid plaques and neurofibrillary tangles (NFTs) and a loss of the connections between cells. Both amyloid plaques and neurofibrillary tangles (NFTs) occur as an accompanying phenomenon of normal aging; however in patients suffering from $\mathrm{AD}$, these two neuropathological markers are present in abnormally large quantities (Kumar et al. 2018). The main component of neurofibrillary tangles is tau protein.

Amyloid precursor protein (APP) is the initial source of the amyloid plaques. The enzymes responsible for cleavage of APP are called alpha-, beta- and gamma secretase. The benign pathway involves cleavage of the APP by $\alpha$-secretase at a critical stage where there is the potential to form amyloid- $\beta$ (A $\beta)$, which thus prevents the latter from being formed (Schedin-Weiss et al. 2014). The pathological pathway involves the participation of $\beta$-secretase (BACE1 ), which first cleaves the APP molecule at one end of the $\mathrm{A} \beta$. BACE- 1 is a transmembrane-bound aspartyl protease and is the major $\beta$-secretase involved in APP metabolism. $\gamma$-Secretase then cuts the remaining fragment of APP which is anchored in the membrane of neuronal cells (MacLeod et al. 2015). Further cleavages result in the release of $A \beta$ into the extracellular space, which then forms aggregates (oligomers) of various sizes.

The amyloid hypothesis ("null hypothesis") was formulated more than 25 years ago and since then, $A \beta$ has been considered to be the main factor in Alzheimer's disease (Selkoe 2001; Bush 2003; Sayre et al. 2001; Varadarajan et al. 2000). However, a complementary hypothesis has been formulated, termed the "alternate hypothesis", which claims that $\mathrm{A} \beta$ is in fact a secondary event (consequence) of the disease, rather than being the initiating factor (Pimplikar 2009). Nonetheless, both hypotheses are in agreement that the $A \beta$ peptide is linked with the formation of reactive oxygen species (ROS). Indeed, various markers of oxidative stress found in the brains of patients with Alzheimer's provide evidence that ROS-induced oxidative stress occurs in AD (Devi and Anandatheerthavarada 2010; Tillement et al. 2010; Block and Calderon-Garciduenas 2009).

The pathogenesis of AD is also associated with the cholinergic system (Kuca et al. 2006), which uses an enzyme acetylcholinesterase (AChE) to catalyze the hydrolysis of the neurotransmitter acetylcholine, into choline and the acetate anion. AChE contains a peripheral anionic binding site (PAS) and a catalytic site (CAS). It has been proposed that acetylcholine firstly binds to the PAS and then rapidly diffuses to the CAS. As the condition of AD progresses, the activity of AChE decreases, while that of the non-specific cholinesterase enzyme, butyrylcholinesterase (BuChE), increases. Increased activity of BuChE is linked with the aggregation of the A $\beta$ peptide (Geula and Darvesh 2004). Current pharmacotherapy for patients suffering from $\mathrm{AD}$ is based on the enhanced cholinergic neurotransmission which is attained by application of cholinesterase inhibitors (ChEI).

Evidence for another critical pathology associated with $\mathrm{AD}$, which is termed metal-induced oxidative stress, has been obtained from the precise quantification of redoxactive transition metals such as iron $(\mathrm{Fe})$ and copper $(\mathrm{Cu})$, and the redox-inactive metal, zinc $(\mathrm{Zn})$, in the brain tissues (Rajendran et al. 2009; Valko et al. 2016). The detailed application of specific physical techniques, which include scanning transmission ion microscopy, Rutherford back scattering spectrometry and particle-induced X-ray emission, revealed an enhanced concentration of $\mathrm{Cu}, \mathrm{Fe}$ and $\mathrm{Zn}$ in the amyloid plaques (Rajendran et al. 2009): thus, the levels of copper and zinc were found to be nearly treble and iron nearly double those in the surrounding tissues. Irrespective of the precise multifactorial origin of $\mathrm{AD}$, these data support the hypothesis that metal-induced oxidative stress plays an important role in the pathology of the disease (Butterfield and Halliwell 2019).

Currently approved drugs for the clinical treatment of Alzheimer's disease are inhibitors of AChE, such as donepezil (recommended dose $5-10 \mathrm{mg} /$ day), rivastigmine (recommended dose 1.5-6 mg/day), and glutamate (recommended dose 16-24 mg/day), and, less commonly used, the uncompetitive antagonist of the $N$-methyl-D-aspartate receptor, memantine (recommended dose 5-20 mg/day), which blocks the flow of the charged species. In addition to various side effects of these drugs, which include diarrhea, nausea, bradycardia and hepatotoxicity, their serious limitation is that the symptoms are improved only temporarily, and that it is not possible to inhibit or reverse the progression of the disease. Even though $\mathrm{A} \beta$ is one of the key biomarkers of $\mathrm{AD}$, administration of the antiamyloid $\beta$ monoclonal antibodies, bapineuzumab and solanezumab (phase III trials) failed to improve cognitive functions in patients suffering from $\mathrm{AD}$ (Wang et al. 2016).

As discussed above, proteolytic formation of neurotoxic A $\beta$ from APP is the critical event in the development of Alzheimer's disease. During this process, both $\beta$-secretase and $\gamma$-secretase play important roles, and accordingly, the secretase inhibitors, semagacestat and avagacestat, have been developed and tested with the aim of suppressing the formation of $A \beta$. However, the results were not fully convincing and serious side effects arose (Doody et al. 2013; Coric et al. 2015). Tau is a multifunctional protein involved in the stabilization of microtubules, and because it plays a critical role in $\mathrm{AD}$, attention has been targeted both on 
the protein itself and its phosphorylation, but yet again with limited success (Kumar et al. 2015).

It has been suggested that dysfunction of the dopaminergic system in the mesolimbic pathway is related to the "positive symptoms' of schizophrenia. Different levels of dopamine dysfunction can also occur in the course of all phases of AD (Martorana and Koch 2014). The most frequent symptoms typical for dysfunction of dopamine systems are the extrapyramidal signs and apathy. Dopamine-related symptoms involve cognitive decline and neuronal degeneration linked with the presence of oxidative stress. Clinical application of dopaminergic drugs, involving mainly DA-D2 agonists such as rotigotine, exhibit improved cognitive functions in Alzheimer's patients (Koch et al. 2014). Further research and clinical trials are needed to clarify the potential therapeutic outcomes of dopaminergic therapy in patients with AD. In addition, attention should be focused on the role of dopaminergic dysfunction in cognitive decline of patients with AD.

The complex pathophysiological mechanisms of Alzheimer's disease require a targeted selection of drugs that can suppress early pathogenic alterations and prevent and/ or alter the natural course of the disease's progression. As outlined above, disturbed metal homeostasis results in metalinduced oxidative stress, which is documented by a number of oxidative stress markers in the brains of AD patients. Oxidative stress is an integral pathology in a range of agedependent diseases such as cancer, cardiovascular disease and various neurological disorders, including Alzheimer's disease. Despite the contradictory and insufficiently convincing reports on the possible beneficial effects of supplements to suppress oxidative stress, it appears that naturally occurring antioxidants in vegetables and fruits, when supplemented with multiple antioxidants, may be very effective in combating some of the harmful effects linked with oxidative stress, especially in the early stages of the development and progression of the disease. The aim of this review is to discuss the role of (metal-induced) oxidative stress and other pathologies in $\mathrm{AD}$ and prospective therapeutic approaches, which employ synthetic and/or natural antioxidants either as individual supplements or as an integral component of bifunctional/multifunctional drugs to adjust any oxidant/ antioxidant imbalance in AD.

\section{Metallobiological aspects of oxidative stress in Alzheimer's disease}

Redox-active ( $\mathrm{Fe}, \mathrm{Cu})$ and redox-inactive $(\mathrm{Zn})$ metals are required for the function of enzymes, which play key roles in various physiological processes. Oxidative stress is a common denominator in various metal-overload diseases such as Wilson's disease (copper) and hemochromatosis (iron), or diseases with perturbed metal homeostasis such as $\mathrm{AD}$, which disturbs the compartmentalization of metal ions (Poprac et al. 2017).

\section{Copper- and iron-induced formation of ROS}

The concentration of copper and iron varies between different regions of the brain (Roberts et al. 2012), and thus while healthy neuropils contain approximately $79 \mu \mathrm{M}$ of copper, in $\mathrm{AD}$, due to the association of copper with senile plaques, its level is substantially decreased (Deibel et al. 1996). Hence, in the brains of Alzheimer's patients, copper is pathologically transferred to the senile plaques, which causes a copper deficiency to arise in the brain cells. Applying a combination of three physical techniques, namely scanning transition microscopy, scattering spectrometry and proton-induced X-ray emission, significantly increased concentrations of metals in the amyloid plaques were identified: thus, while the concentration of iron was found to be doubled, the concentration of copper was trebled and that of zinc almost trebled, as compared with the surrounding tissue (Rajendran et al. 2009).

While the precise quantification of total $\mathrm{Fe}$ or $\mathrm{Cu}$ (and also non-redox $\mathrm{Zn}$ ) levels remains a matter of debate, it may be less important to know the exact total amounts of iron or copper, than to know the ratio of $\mathrm{Fe}^{3+}$ to $\mathrm{Fe}^{2+}$ or $\mathrm{Cu}^{2+}$ to $\mathrm{Cu}^{+}$species.

Free, or non-chelated, iron or copper are the main components of the "labile metal pools" which can catalyze the formation of damaging ROS via the Fenton reaction (Valko et al. 2005) (Eq. 1):

$\mathrm{Fe}^{2+} / \mathrm{Cu}^{+}+\mathrm{H}_{2} \mathrm{O}_{2} \rightarrow \mathrm{Fe}^{3+} / \mathrm{Cu}^{2+}+\mathrm{OH}+\mathrm{OH}^{-}$.

The formation of hydroxyl radicals via the Fenton reaction requires hydrogen peroxide, which is produced by the removal of the superoxide radical anion $\left(\mathrm{O}_{2}^{-}\right)$, the latter being generated under physiological conditions by the activated enzyme NADPH oxidase, to kill oxygen-dependent pathogens. Physiologically balanced levels of superoxide radical anion are maintained via the dismutation reaction (Eq. 2) (Halliwell and Gutteridge 2007):

$2 \mathrm{O}_{2}^{--}+2 \mathrm{H}^{+} \stackrel{\text { SOD }}{\longrightarrow} \mathrm{H}_{2} \mathrm{O}_{2}+\mathrm{O}_{2}$,

which is catalyzed by the superoxide dismutase (SOD) enzymes that function in conjunction with hydrogen peroxide-removing enzymes, such as catalase (Matés et al. 1999) (Eq. 3):

$2 \mathrm{H}_{2} \mathrm{O}_{2} \stackrel{\text { Catalase }}{\longrightarrow} \mathrm{H}_{2} \mathrm{O}+\mathrm{O}_{2} \quad k=7.0 \times 10^{9} \mathrm{M}^{-1} \mathrm{~s}^{-1}$,

and glutathione peroxidases (GPx) (Halliwell and Gutteridge 2007; Matés et al. 1999) (Eq. 4):

$\mathrm{H}_{2} \mathrm{O}_{2}+2 \mathrm{GSH} \stackrel{\text { GPx }}{\longrightarrow} \mathrm{H}_{2} \mathrm{O}+\mathrm{GSSG}$, 
where glutathione (GSH) is oxidized to glutathione disulfide (GSSG).

The superoxide radical anion may reduce ferric ions to ferrous species, yielding molecular dioxygen in the process:

$\mathrm{Fe}^{3+}+\mathrm{O}_{2}^{--} \rightarrow \mathrm{Fe}^{2+}+\mathrm{O}_{2}$.

By combining the equations for the Fenton reaction (1) and reaction (5), an overall reaction known as the Haber-Weiss reaction is obtained (Valko et al. 2004) (Eq. 6):

$\mathrm{O}_{2}^{--}+\mathrm{H}_{2} \mathrm{O}_{2} \rightarrow \mathrm{O}_{2}+\mathrm{OH}+\mathrm{OH}^{-}$.

The shielding of redox-active metals such as copper and iron plays an important role in preventing metal-induced oxidative stress. The binding of natural substances via coordinating atoms such as oxygen, nitrogen or sulfur to redox metals blocks their catalytic activity to form ROS via Fenton chemistry. Since the maximal coordination number of iron and copper is six, the hexadentate chelators can provide catalytically more inert complexes than free metal ions due to their ability to completely saturate the coordination sphere around redox ions. Thus, a suitable proposed biologically active molecule that binds to all six sites of redox ions catalytically deactivates the free (unbound) metal ions. There are many examples of chelators that inhibit the catalytic reactions with the participation of redox metals (Lovejoy and Richardson 2003). Flavonoids or some alkaloids have a strong affinity for redox-active metal ions such as $\mathrm{Cu}$ (II) and $\mathrm{Fe}$ (II) and thus may affect metal-induced DNA damage. Generally, the more favorable the interaction between the redox metals and the flavonoids, the more profound is the antioxidant activity observed. While interactions of ferrous ions and flavonoids result in a very effective mechanism of DNA damage prevention, interactions of flavonoids with cuprous ions is much weaker and do not give rise to effective antioxidant activity and, in fact, may even promote DNA damage via excessive ROS formation (Perron et al. 2011).

The pathways for the formation of ROS and their elimination by antioxidants and antioxidant enzymes are depicted in Fig. 1.

\section{Redox-active copper and iron in AD}

The "null hypothesis" in Alzheimer's disease has been focused predominantly on A $\beta$ (Braak and Braak 1991) and thus the increased formation of $A \beta$ as a preventive antioxidant for brain lipoproteins under the conditions of oxidative

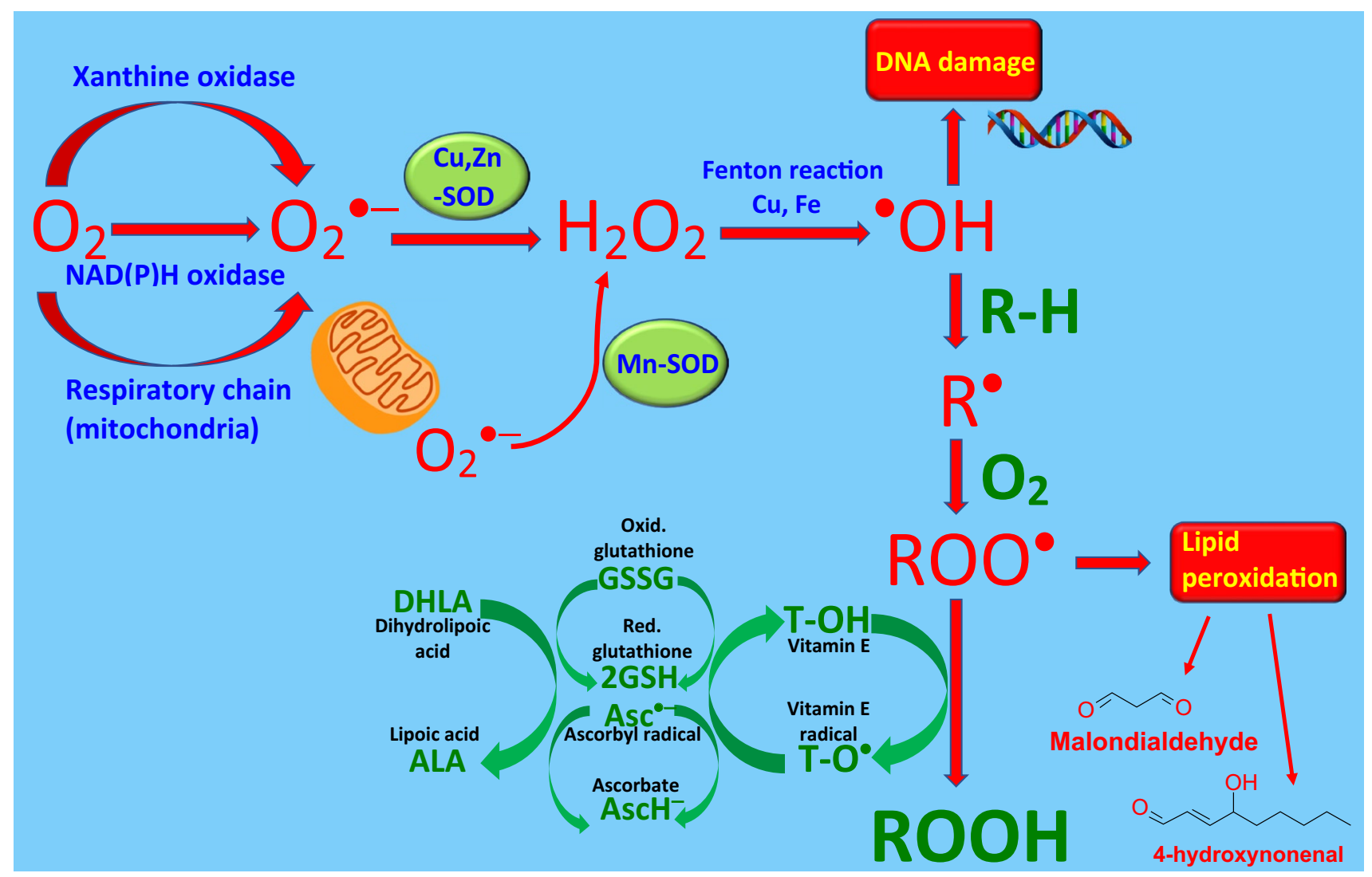

Fig. 1 Various pathways of ROS formation and their elimination by antioxidant defense mechanisms 
stress is proposed to be a key phenomenon in the incidence of AD (Hardy and Selkoe 2002).

The neurotoxicity of $A \beta$ is closely connected with the length and conformation of the peptide chain (Atwood et al. 1998). $A \beta(1-42)$ is the most abundant species in amyloid plaques and is more toxic than $A \beta(1-40) ; A \beta(1-42)$ also has the greatest aggregation ability and affinity toward cupric ions and is furthermore a major source of hydrogen peroxide and ROS. A $\beta$ aggregates into two conformational states: the cytotoxic ordered fibrillary $\beta$-sheet and the benign amorphous non-fibrillar non- $\beta$-sheet (Chafekar et al. 2007). The neurotoxicity of $\mathrm{A} \beta$ is associated with its aggregation properties. The process of aggregation is strongly influenced by the peptide concentration, the $\mathrm{pH}$ of its local environment and by the relative concentrations of iron, copper and zinc there.

The general view that $A \beta$ is toxic of itself has recently been challenged and it has been demonstrated that it is not toxic in the absence of redox metal ions (Huang et al. 1999). Hence, it may be concluded that the signs of oxidative damage detected in $\mathrm{A} \beta$ are a direct consequence of the presence of the redox-active metals, copper and iron (Valko et al. 2005; Bush and Curtain 2008). Indeed, $A \beta$ has a high affinity toward copper and iron and has been shown that it can reduce both these metals, with the subsequent formation of hydrogen peroxide and oxidized amyloid (Cuajungco et al. 2000; Huang et al. 1999; Hung et al. 2010). Since the toxicity of $A \beta$ is associated with its ability to form hydrogen peroxide (Valko et al. 2005) and other ROS, this may be suppressed by the administration of antioxidants and free radical scavengers (Halliwell 2001).

Oxidative stress/damage in AD is characterized by the upregulation of antioxidant enzymes, and most sensitively by the elevation of levels of heme oxygenase-1 (HO-1) (Premkumar et al. 1995). A recent study has identified RNA as a major target for oxidative damage in patients with AD, for which mitochondrial dysfunction and elevated levels of 8-hydroxy-guanine - a sensitive marker of oxidative damage-are collectively responsible (Valko et al. 2006).

A $\beta$ participates in the oxidation of membrane lipids, which results in the formation of 4-hydroxynoenal (Ciccotosto et al. 2004; Smith et al. 2006), a compound that has been shown to modify histidine units in $\mathrm{A} \beta$ via covalent bonding. A cellular deficiency of copper results in the localization of amyloid on cholesterol rich lipid rafts, thus forming a favorable environment for the formation of $\mathrm{Cu}-\mathrm{A} \beta$ complexes (Hung et al. 2009).

The catalytic action of copper ions results in the oxidation of several amino acids on the side chains of $A \beta$, as has been demonstrated by the formation of methionine sulfoxide and methionine sulfone at position 35 (Ciccotosto et al. 2004; Ali et al. 2005) and by the modification of lysines at positions 16 and 28 (Chen et al. 2007). Various oxidation products of histidine and N3-pyroglutamate have been detected in amyloid plaques, while in addition, tyrosine at position 10 is another target for redox metal-induced redox reactions (Barnham et al. 2004; Haeffner et al. 2005) and a variety of tyrosine modifications (Reynolds et al. 2005).

As discussed above, it has been documented that the $\mathrm{N}$-terminal residues of histidine (His13, His14, His6) and tyrosine (Tyr10) participate in the complexation of copper ions with $\mathrm{A} \beta$ (Cerpa et al. 2004). It has been suggested that the $\mathrm{N}$-terminal end of $\mathrm{A} \beta$ is complexed with cupric ions which results in the formation of the

Met-S $+\mathrm{A} \beta-\mathrm{Cu}(\mathrm{II}) \leftrightarrow \mathrm{Met}^{-\mathrm{S}^{+}}+\mathrm{A} \beta-\mathrm{Cu}(\mathrm{I})$

sulfide radical of Met35 (Met-S ${ }^{+}$), accompanied by the reduction of cupric ions to cuprous species (Eq. 7). As is clear from the reaction (7), the process of metal reduction requires the one-electron oxidation of methionine which results in the formation of radical cation (Met-S ${ }^{+}$), and which has been proposed to play a role in the neurotoxicity of $A \beta$ with the subsequent formation of more ROS.

In spite of the fact that thermodynamic calculations, based on the half-cell reduction potentials of the cupric/ cuprous and Met/Met-S ${ }^{+}$couples, show that the reaction (7) is rather unfavorable, electron transfer from Met-S to $\mathrm{A} \beta-\mathrm{Cu}(\mathrm{II})$ may be assisted by the exergonic deprotonation reaction of MetS ${ }^{-+}$, thus making the reaction (7) feasible under in vivo conditions (Pogocki 2003; Valko et al. 2005).

The Met-S ${ }^{+}$radical cation may be stabilized via the formation of a three-electron sulfur-sulfur bond (Cerpa et al. 2004), since theoretical calculations have predicted the formation of an S.:O bond in $\mathrm{A} \beta$, where the notation ".:" indicates a three-electron bond, in which two electrons occupy a bonding $\sigma$-orbital, while the third electron is located in a the $\sigma^{*}$ antibonding orbital. The Met- $\mathrm{S}^{++}$radical cation may also react very rapidly with $\mathrm{ROS}$, for example with superoxide radical anions, to form Met-sulfoxide (MetSO) as a product, which has been detected in AD senile plagues (Cerpa et al. 2004; Pogocki 2003):

$\mathrm{MetS}^{\cdot+}+\mathrm{O}_{2}^{-\stackrel{\text { Met }}{\longrightarrow}} 2 \mathrm{MetSO}$

In conclusion, amyloid plaques are rich in a variety of oxidized A $\beta$ species, and since methionine is highly prone to oxidative damage under in vivo conditions, this residue is closely linked with the pathogenesis of AD. Oxidation of Met35 to Met-sulfoxide has a consequence of reducing toxic and pro-apoptotic effects of the $\mathrm{A} \beta$ protein fragment on isolated mitochondria.

ROS are involved in the process of lipid peroxidation and are responsible for the formation of a variety of reactive carbonyl compounds. The latter can react further with very important biological molecules such as proteins, lipids and DNA, to cause such phenomena as 
protein cross-linking and DNA damage. During the course of these reactions, a variety of advanced glycation (AGE) and advanced lipid (ALE) peroxidation end products are formed (Sayre et al. 2001; Chafekar et al. 2007), which may further trigger activation of signaling pathways such as those involving proinflammatory cytokines (interleukin-6) (Valko et al. 2005). ROS-mediated lipid peroxidation of polyunsaturated fatty acids results in the formation of various reactive aldehydes, among which 4-hydroxytrans-2-nonenal (HNE), 4-oxo-trans-2-nonenal (4-ONE), acrolein and 4-oxo-trans-2-hexenal are well-known neurotoxic agents.

An interesting correlation between cholesterol levels and AD has been proposed. High levels of cholesterol in the blood can increase both the aggregation of $A \beta$ and the brain iron load, which may catalyze oxidative damage. Thus, hypercholesterolemia has been proposed to be a potential risk factor for AD (Ong and Halliwell 2004).

\section{Redox-inert zinc in AD}

In micromolar concentrations, zinc is able to inhibit A $\beta$-induced toxicity (Cuajungco et al. 2000; Maret 2019; Dong et al. 2006; Deshpande et al. 2009; Garai et al. 2007). While the protective mechanism of zinc against the $A \beta$ toxicity is not fully known, it has nonetheless been proposed that the cytoprotection is assisted by blocking the membrane calcium channel pore formed by $\mathrm{A} \beta(1-40)$.

Further roles of zinc in AD are closely associated with copper (Cuajungco et al. 2000). Zinc is able to compete with copper (and partly with iron) and bind tightly to $A \beta$, so changing its conformational state to such an extent that copper ions are unable to access its binding sites. The inability of copper ions to reach the binding sites (copper and zinc share binding sites), due to their saturation by zinc, results in the prevention of copper-A $\beta$-induced formation of ROS.

Various exogenous and endogenous factors that result in the induction of both oxidative and nitrosative stress may in turn trigger the pathological metabolism of $A \beta$, which is accompanied by uncontrolled flooding of the vesicular zinc pool (Cuajungco and Lees 1998). Taken together, while low levels of zinc may protect against $\mathrm{A} \beta$ toxicity, excess of zinc induced by oxidative stress could be responsible for neuronal death. In support of this, it has been confirmed that the interaction of $A \beta$ with high concentrations of zinc is responsible for the precipitation of the $A \beta$ (Cuajungco and Faget 2003).

From the above, discussion it follows that a delicate balance between the metabolism of $A \beta$ and copper and zinc is maintained exclusively under normal physiological conditions. However, under conditions of oxidative and nitrosative stress, this balance is disturbed and is followed by the deposition of amyloids and elevated zinc pools.

\section{Combating oxidative stress and other pathologies in AD}

As discussed above, AD is multifactorial in origin and involves three main pathologies: (1) a deficiency of acetylcholine, caused by the aberrant activity of an enzyme AChE, (2) the formation of extracellular amyloid plaques and neurofibrillary tangles and (3) (metal-induced) oxidative stress. Here, we discuss predominantly those drugs which suppress the oxidative stress component of AD, either by acting as individual molecules or as an active part of a multifunctional drug.

\section{Multifunctional drugs containing metal-chelating and oxidative stress-suppressing moiety}

The key therapy against AD is based on the application of centrally acting AChE inhibitors to compensate for the cholinergic deficit in the brain. AChE is found primarily in the blood and in the neural synapses, and has been shown to be the most viable therapeutic target to improve the symptoms of $\mathrm{AD}$. In addition to $\mathrm{AChE}$, the liver contains butyrylcholinesterase (BuChE) (Mehta et al. 2012). Most of the available drugs for the treatment of AD target both $\mathrm{AChE}$ and BuChE; however, some of them are more selective than others. Historically, the first ChEI was the alkaloid, physostigmine, isolated from the seeds of Physostigma venenosum, but the drug exhibited many side effects and was accordingly abandoned for the treatment of AD (Orhan et al. 2009). Tacrine was the first drug approved for the treatment of $\mathrm{AD}$, and was introduced in 1993 (Tumiatti et al. 2010); however, due to its various side effects, its widespread application was limited and a series of new drugs were approved after 1995, including donepezil, rivastigmine and galantamine.

To address the multifactorial nature of $\mathrm{AD}$, a new approach, based on the application of "one moleculemultiple targets", has recently attracted the wide interest of scientists. A variety of drugs, called multitarget-directed ligands (MTDLs), which are capable of acting at the various neuropathological levels of $A D$, have been prepared and studied. Such a hybrid usually consists of two chemically and pharmacologically different molecules that are connected by a linker unit of varying size and chemical type (Girek and Szymanski 2019). Multifunctional drugs combine BBB permeability with the ability to target multiple receptors, as a means to combat those key pathologies that are typical for AD.

Since tacrine has demonstrated very mild improvements in the cognitive functions of $\mathrm{AD}$ patients, medicinal chemists were prompted to undertake the design and testing of 
hybrid molecules containing tacrine and an antioxidant moiety. Such a multipotent approach toward targeting the oxidative stress component in AD included the introduction of novel tacrine-melatonin (Spuch et al. 2010), tacrine-coumarin (Hamulakova et al. 2014), tacrine-gallamine (Elsinghorst et al. 2007), tacrine-resveratrol (Jerabek et al. 2017), tacrine-scutellarin (Spilovska et al. 2017), tacrine-anisidine (Korabecny et al. 2015), tacrine-trolox (Nepovimova et al. 2015) and related hybrid molecules (Fig. 2).

Melatonin is a hormone, produced by the pineal gland that is involved in the synchronization of the circadian rhythms. It has additionally been shown to act as a highly effective scavenger of hydroxyl radicals, superoxide radicals and nitric oxide and is also one of the most efficient lipophilic antioxidants known. From a study which evaluated the influence of tacrine-melatonin hybrids on the behavior and neuropathologic changes in APP transgenic mice (Spuch et al. 2010), it was shown that administration of such drugs caused a significant reduction in $\mathrm{A} \beta$ deposits. On the basis of an object recognition test, it was revealed that the application of the hybrids also alleviated several behavioral deficits, including short-term memory loss, which indicates that a remarkable neuroprotective effect is in operation and thus a potential therapeutic strategy for the treatment of $\mathrm{AD}$ is identified. Using the same tacrine-melatonin hybrids, in another study (Rodríguez-Franco et al. 2006) some very promising antioxidant activity against oxygen radicals was reported, as determined by the ROS-absorbance capacity assay, which used fluorescein. One additional result from this study was that a dichloro-derivative of tacrine linked with melatonin is a more powerful inhibitor of $\mathrm{AChE}$ than tacrine by a factor of 40,000 .

Coumarin is found in many plants and since it inhibits the synthesis of vitamin $\mathrm{K}$, it is used therapeutically as an anticoagulant. A variety of tacrine-coumarin hybrids were prepared and characterized as potential drugs for the treatment of AD (Xie et al. 2013; Xie et al. 2015). Different derivatives of coumarin with different types and lengths of the tacrine-coumarin linkers have been used. The coumarin moiety is active against aggregation of $A \beta$, the tacrine moiety is active against inhibition of AChE and BuChE and the linker, which contains oxygen and nitrogen donors, is involved in the chelation of redox-active metal ions. In our
Fig. 2 Structures of ligands used for the synthesis and studies of tacrine hybrids<smiles>Nc1c2c(nc3ccccc13)CCCC2</smiles>

Tacrine<smiles>Oc1ccc(/C=C/c2cc(O)cc(O)c2)cc1</smiles>

Resveratrol<smiles>Cc1c(C)c2c(c(C)c1O)CCC(C)(C(=O)O)O2</smiles>

Trolox

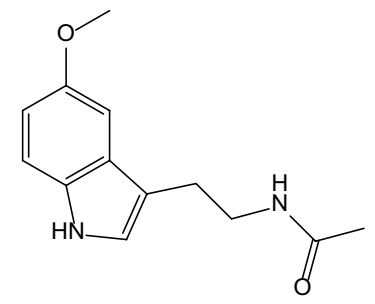

Melatonin<smiles>O=C(O)CC1OC(Oc2cc3oc(-c4ccc(O)cc4)cc(=O)c3c(O)c2O)C(O)C(O)C1O</smiles>

Scutellarin<smiles>Oc1ccccc1-c1nc2ccccc2[nH]1</smiles>

2-(2-Hydroxyphenyl)-1H benzimidazole
Coumarin<smiles>COc1ccc(N)cc1</smiles>

p-Anisidine<smiles>O=c1ccc2ccccc2o1</smiles> 
own group, we studied tacrine-7-hydroxycoumarin hybrids linked by polyamine tethers of different lengths via an amide functionality (Hamulakova et al. 2016). It was found that the compounds exhibited a significant activity toward the inhibition of hAChE $\left(\mathrm{IC}_{50}=38 \mathrm{nM}\right)$ and hBuChE $\left(\mathrm{IC}_{50}=63 \mathrm{nM}\right)$, and a greater than $50 \%$ inhibitory effect against $\mathrm{A} \beta$ was observed for several compounds with different lengths of the linker. With respect to the oxidative stress component of $\mathrm{AD}$, interaction of the hybrid compounds with $\mathrm{Cu}$ (II) ions and the formation of free radicals were studied using EPR spectroscopy. The results confirmed that reduction of cupric to cuprous species occurred upon interaction with the hybrids, while EPR spin trapping experiments (with DMPO as the spin trap), using the model Fenton reaction, confirmed that the formation of hydroxyl radicals was significantly suppressed, in comparison with a system containing free copper ions. Hence, a potential protective effect of the hybrid molecules against free metal (copper)-catalyzed formation free radicals, which results in oxidative stress in AD brain, is indicated. The protective activity of tacrine-coumarin hybrids against DNA damage in a model Fenton system was in accordance with the conclusions drawn from the EPR spectroscopic measurements (Hamulakova et al. 2016).

There have been very few investigations made of such hybrid drugs which interact simultaneously with a cholinergic system and muscarinic acetylcholine receptor $\mathrm{M}_{2}$, which use $\mathrm{G}$ proteins in their signaling pathway, even though many types of neurons respond sensitively to stimulation of muscarinic receptors. In one such study (Elsinghorst et al. 2007; Romero et al. 2013), it was found that while gallamine itself did not exhibit significant antioxidant properties, in the form of a hybrid, where it interacted with a cholinergic system and a muscarinic choline receptor, it was a very effective inhibitor of $\mathrm{AChE}$, with $\mathrm{IC}_{50}=500 \mathrm{pm}$.

Resveratrol is a natural phenolic compound occurring in red wine, blueberries, grapes and other fruits, which has been documented to exhibit protective effects against metalinduced oxidative stress in cerebro-cardio-vascular systems (Carrizzo et al. 2013). Thus, resveratrol has been found to suppress cognitive and motor impairment, neuroinflammation, apoptosis, DNA damage, and oxidative and nitrosative damage (Singh et al. 2013). In tacrine-resveratrol hybrids, tacrine functions as a cholinesterase-inhibiting moiety, while the resveratrol moiety acts as an antioxidant and neuroinflammatory suppressor; it is also an effective antiaggregation modulator of $\mathrm{A} \beta$ and a ChEI at micromolar concentrations.

Scutellarin is a herbal flavonoid which occurs in the Chinese traditional herb Erigeron breviscapus Hand-Mazz and has several beneficial effects on human health, based on antioxidant, antiinflammatory and cardioprotective properties along with other positive features. New derivatives and improved formulations have been developed to improve the bioavailability and effectiveness of scutellarin, and thus a series of 6-Cl-tacrine-scutellarin hybrids was prepared and studied as potential therapeutic agents for the treatment of AD. On the basis of a DPPH assay it was determined that the hybrids exhibit weaker radical-scavenging (antioxidant) activities than the Trolox standard. The scutellarin molecule contains $-\mathrm{OH}$ groups which are assumed to be responsible for its radical-scavenging activity; however, the phenolic $-\mathrm{OH}$ groups of the scutellarin molecule are hindered by $-\mathrm{OCH}_{3}$ groups in the hybrids, which thus prevents them from manifesting their antioxidant effects under the conditions of the DPPH assay.

Docking calculations revealed that the scutellarin functionality protrudes out of the cavity gorge, while the tacrine functionality interacts with the CAS of AChE. A similar stereochemical orientation has also been reported for tacrine-tianeptine or 7-methoxytacrine-adamantylamine hybrids (Ceschi et al. 2016; Spilovska et al. 2013; Korabecny et al. 2015). An opposite arrangement, in which tacrine interacts with PAS has been reported for 7-methoxytacrine- $p$-anisidine (Korabecny et al. 2015), 7-methoxytacrine-donepezil (Misik et al. 2015) and tacrine-trolox heterodimers (Nepovimova et al. 2015).

$p$-Anisidine is known to suppress intracellular accumulation of the precursor to the neurotoxic A $\beta$, APP. $p$-Anisidine has been used to synthesize 7-methoxytacrine- $p$-anisidine hybrids as potential dual-binding site AChE inhibitors for the treatment of Alzheimer's disease (Korabecny et al. 2015). Both functionalities were linked with an alkyl tether containing urea/thiourea molecules. With respect to inhibitory activity against $\mathrm{AChE}$, the hybrids were slightly more active than 7-methoxytacrine and less active than tacrine. Interestingly, those hybrids with longer linkers displayed a greater inhibitory activity toward AChE.

Trolox is a synthetic water-soluble analog of vitamin $\mathrm{E}$ that exhibits very efficient radical-scavenging activity and the Trolox Equivalent Antioxidant Capacity (TEAC) assay is used to determine the antioxidant/radical scavenging of a given compound (or extract) with respect to trolox as a standard. Thus, trolox has been used to prepare tacrine-trolox hybrids with the aim of alleviating metal-induced oxidative stress in $\mathrm{AD}$. While some of the resulting compounds were found to have slightly better cholinesterase activity than the reference molecule tacrine, more importantly, it was noted that these hybrids could block the PAS of the AChE which is connected to the neurotoxic pathways of $\mathrm{AD}$ via AChEinduced aggregation of $A \beta$. Docking calculations revealed that while the trolox moiety interacts with CAS, the tacrine functionality binds to the PAS of the AChE. On the basis of a DPPH assay, it was determined that due to the excellent radical-scavenging ability of the trolox functionality, these compounds were able to alleviate ROS-induced oxidative stress. 
Benzimidazoles are compounds that can exert various biological effects. With the aim of addressing several pathologies in $\mathrm{AD}$, the hydroxyphenylbenzimidazole functionality was incorporated into the series of tacrine-hydroxyphenylbenzimidazole hybrids (Hiremathad et al. 2018). The latter compounds were found to exhibit excellent AChE inhibitory activity at nanomolar concentrations and are more strongly active in this regard than is the parent tacrine. They also inhibited copperinduced and self-induced aggregation of $\mathrm{A} \beta$ and showed mild radical-scavenging/antioxidant activity and metalchelating efficiency; furthermore, the hybrids were able to inhibit $A \beta$ and iron/ascorbate-induced neurotoxicity in neuronal cells.

Ferulic acid is a hydroxycinnamic acid present in plant cell walls. The presence of two hydroxyl groups in the molecular structure predetermines the ferulic acid to be an effective antioxidant. In line with this, several tacrine-ferulic acid hybrids have been prepared and studied as potential drugs for the treatment of AD (Zhu et al. 2018). Hybrids have been shown to be active inhibitors of both AChE and $\mathrm{BuChE}$ in the nanomolar range. In addition, the compounds significantly inhibited the self-induced aggregation of $A \beta$ and showed antioxidant activity. In vivo evaluation of hybrids using Morris water navigation task confirmed that some of the hybrids significantly improved memory in the scopolamine-induced cognitive impairment. Taken together, ferulic acid appears to be a promising agent for further investigation.

The aim is to develop multitarget agents that meet the criteria for clinical testing for AD. However, clinical application of MTDL therapy faces several problems, such as too high molecular mass of hybrids and their problematic penetration through the CNS barrier. In addition, the concentration of inhibitor in in vitro assay may be significantly different from the optimal concentration for use under in vivo conditions. For example, inhibitor 7-methoxytacrine (7-MEOTA), which shows cellular toxicity under in vitro assays, surprisingly, does not exhibit hepatotoxicity in the in vivo assays (Girek and Szymanski 2019; Nepovimova et al. 2015). In the course of in vivo tests, it is important to evaluate the value of the median lethal dose of hybrid molecules. Critical toxicity concentrations of novel hybrids should also be determined within the in vivo tests. To achieve all these goals, attention should be focused on deeper understanding of the mechanism of action of multitarget drugs (Prati et al. 2016). This will require robust pharmacokinetic and pharmacodynamic data confirming whether the drug crosses effectively BBB and simultaneously modulates multiple targets. In a recent paper, it has been suggested that the $A \beta$ hypothesis, which has been formulated more than 20 years ago, should have been rejected because of the limited progress that has been made (Herrup 2015). In fact, potentially more promising targets, such as tau protein, have been studied relatively scarcely.

In conclusion, most of these hybrid compounds are potent inhibitors of $\mathrm{AChE}$ and $\mathrm{BChE}$ and also of $\mathrm{A} \beta$ aggregation. In addition, the antioxidant functionality, represented by coumarins, melatonin and other antioxidant molecules, reduces the level of oxidative stress via ROS-scavenging mechanisms as well as via chelation of redox-active $\mathrm{Cu}$ and $\mathrm{Fe}$. Chelated metal ions exhibit a suppressed catalytic activity in various reactions, including the Fenton reaction (1) which is the origin of hydroxyl radical formation that causes damage to neurons.

\section{Herbal drugs}

The therapeutic potency of the herbal drugs is manifested predominantly by (1) their inhibitory activity against AChE, (2) antioxidant or radical-scavenging and redox metalchelating activities, (3) inhibition of $A \beta$ aggregation, $\tau$ protein hyperphosphorylation and (4) antiinflammatory activity. The entry of drugs to the CNS from the circulatory system is governed by the blood-brain barrier (BBB) (Wang et al. 2016), and crossing the BBB is a critical issue for AD drugs, although many single compounds extracted from herbs have been found to do this and thus manifest their therapeutic potency in the brain (Fig. 3).

Huperzine A is an alkaloid, which occurs naturally in the plant, Huperzia serrata, and is a selective and reversible inhibitor of AChE. It has been shown that of two bifunctional hybrids, donepezil-huperzine A was less effective, while tacrine-huperzine A was more effective as an inhibitor of AChE, under in vitro conditions, than the parent tacrine. Huperzine A has better oral bioavailability than donepezil or tacrine and engenders more beneficial effects on short-term memory than on long-term memory. Huperzine A improves both the cognitive functions and the memory of patients with $\mathrm{AD}$, without causing side effects, and is marketed in the USA as a nutraceutical cognitive enhancer.

Huperzine A exhibits antioxidant properties and decreases the levels of BACE1 and APP695 proteins; accordingly, it is also able to reduce the incidence of $A \beta$ hyperphosphorylation of $\tau$ protein in the hippocampus and cerebral cortex in transgenic mice with AD (Huang et al. 2014).

Natural huperzine B is an alkaloid isolated from the same Chinese medicinal herb as huperzine A. While huperzine B is less active than huperzine A (Shi et al. 2009), several derivatives of huperzine $B$ have been found to show a greater potency, and are more active than huperzine A, galantamine or rivastigmine.

One of the most active inhibitors of $\mathrm{AChE}$ is serpentine, a terpene alkaloid isolated from the Apocynaceae family of flowering plants. This alkaloid has a high anticholinergic potency $\left(\mathrm{IC}_{50}=0.77 \mu \mathrm{M}\right)$ which is related to the binding of 
Fig. 3 Structures of herbal drugs with therapeutic potency against Alzheimer's disease

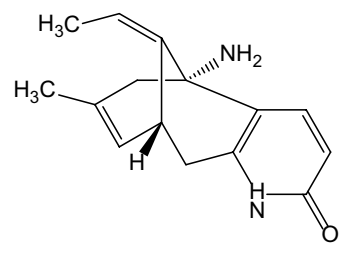

Huperzine A<smiles>CC1=C[C@@H]2Cc3[nH]c(=O)ccc3[C@@]3(C1)NCCC[C@H]23</smiles>

Huperzine B<smiles>COC(=O)C1=COC[C@H]2C[n+]3ccc4c([nH]c5ccccc54)c3C[C@H]12</smiles>

Serpentine

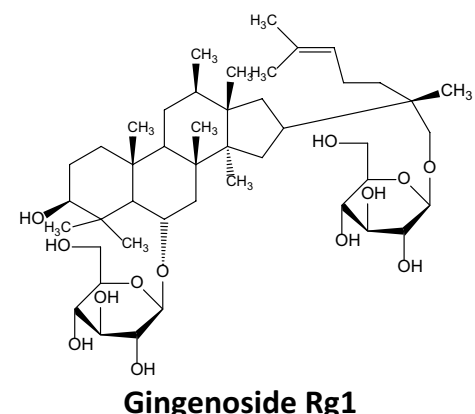<smiles>O=C(O)[C@H](O)Cc1ccc(O)c(O)c1</smiles><smiles>Cc1coc2c1C(=O)C(=O)c1c-2ccc2c1CCCC2(C)C</smiles>

Danshensu

Tanshinone Ila

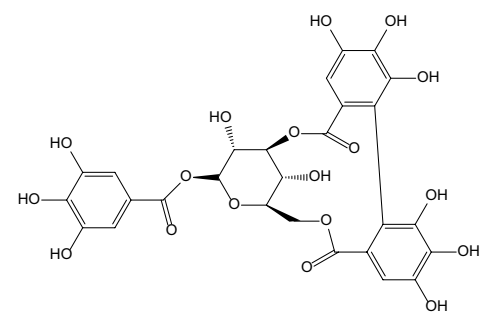

Corilagin<smiles>COc1cc(/C=C/C(=O)CC(=O)/C=C/c2ccc(O)c(O)c2)ccc1O</smiles>

Curcumin its quaternary nitrogen functionality to the aspartate residue of PAS (Pereira et al. 2010).

Ginseng (genus Panax) is the root of plants that grow in Korea (Korean ginseng) and China (Chinese ginseng), and its main active components are ginsenosides and gintonin, which is a glycolipoprotein fraction. There are more than 30 ginsenosides (e.g., Rg1, Rg2) extracted from ginseng, which exert various different biological effects. Many studies have demonstrated that ginsenosides can prevent and improve the symptoms of $\mathrm{AD}$, by regulating antiinflammatory effects, synaptic plasticity, the formation of $\mathrm{A} \beta$ and the activity of $\beta$ secretase (Kim et al. 2013). Ginsenoside Rg1 has been documented to suppress the level of $A \beta$ in the hippocampus of the brains of mice with $\mathrm{AD}$, which resulted in the protection of cholinergic neurons and synapses, along with improved cognitive functions (Fang et al. 2012) The neuroprotective effect of $\mathrm{Rg} 1$ is linked to a suppressed apoptosis of neuronal cells and increased levels of Bcl-2 over Bax, and inhibition of the expression of cytochrome C. (Gong et al. 2011). Ginsenoside $\operatorname{Rg} 3$ inhibits the hyperphosphorylation of $\tau$ protein and the neuroinflammatory response via suppression of inflammatory factors, such as tumor necrosis factor (TNF- $\alpha$ ), interleukin 1 beta (IL-1 $\beta$ ) and cyclooxygenase (COX), which in turn improves both memory and cognitive performance in rats (Lee et al. 2013).

The positive effects of Salvia miltiorrhiza (Danshen) on neurological disorders, including AD, are due to the presence of two types of active components: hydrophilic components, such as danshensu and lipophilic components, such as tanshinone IIA (Lu et al. 2015). Tanshinone IIa significantly protects neurons against metal-induced oxidative stress by several mechanisms: an increase in the concentration of glutathione peroxidase (GPX), direct ROS and RNS scavenging activity, an increase in the level of the membrane potential, a reduction in the toxic effects of malondialdehyde (MDA), a suppression of the activity of superoxide dismutase, an increase in the level of glutathione peroxidase (GSH-PX), and an increase in the amount of the Bcl-2 over Bax with regard to $A \beta$-induced toxicity in the cortical neurons of rats (Liu et al. 2010).

Extracts from danshen (Radix S. miltiorrhiza) are characterized by lipophilic components such as tanshinone IIA and 
hydrophilic components such as salvianolic acid B (Lu et al. 2015; Wang et al. 2016; Weng et al. 2015). Since most of these components protect neurons, they have the potential to be used to combat some of the pathologies that are features of AD. Lipophilic tanshinone IIA has been found to decrease the number of apoptotic PC12 cells via activation of PI3K/ AKt and phosphorylation of GSK3 $\beta$ (Xiuli et al. 2015). However, the most significant effect of tanshinone IIA is against oxidative stress, which is one of the key pathologies in $\mathrm{AD}$ and thus it reduces the formation of ROS, malondialdehyde and the activity of caspase 3. Conversely, tanshinone IIA is found to increase the mitochondrial membrane potential and the ratio of Bcl-2/Bax in cortical neurons (Liu et al. 2010). Danshensu, which is a hydrophilic component of danshen, also has the ability to alleviate some of the symptoms of $\mathrm{AD}$ as a result of reducing oxidative stress: thus, oxidative damage achieved by hydroxydopamine-induced overexpression of PI3K/Akt/Nrf2 has been found to be suppressed through danshen-induced expression of the enzyme, heme oxygenase-1 (Chong et al. 2013). Other active components, such as tanshinone I and its derivatives, as extracted from danshen, show neuroprotective effects (Wong et al. 2010) which involve a reduction both in the uptake of calcium and in the release of lactate dehydrogenase.

Corilagin (gallotannin) was isolated in the early 1950s from Libidibia coriaria, which is a tree that is native to Central America (Li et al. 2018) and in addition to its anticancer and hepatoprotective properties, neuroprotective activities have been demonstrated for this compound. Thus, $A \beta$ has been found to induce extensive formation of ROS and cell cycle arrest in PC 12 cells (Youn et al. 2016), but it was shown that corilagin provided protection of the cells against these damaging effects. Furthermore, the compound resulted in an activation of the transcription factor NF-kappaB, a suppressed formation of inflammatory mediators involving TNF- $\alpha$, and $\mathrm{NO}^{-}$and a downregulation of the inducible enzyme nitric oxide synthase (NOS). Overall, these results indicate a variety of neuroprotective effects for corilagin, which is therefore a promising agent for the prevention and treatment of $\mathrm{AD}$.

Ginkgo biloba is one of the oldest trees on our planet and has been continually cultivated for use in traditional medicine. Representative extracts from the Ginkgo leaf contain $25 \%$ flavonoid glycosides, up to $10 \%$ of organic acids and $3-7 \%$ of terpenoids. Although the exact mechanism of the action of gingko is not fully understood, it is known that protection of cells from oxidative damage is provided by an optimization of blood flow and the scavenging of ROS. Gingko is able to function as a neuroprotective agent as a result of the preservation of mitochondrial function, antiinflammatory activity and the suppression both of neuronal apoptosis and $\mathrm{A} \beta$ aggregation (Shi et al. 2010). The antioxidant action of gingko results from increased levels of antioxidants such as glutathione and/or antioxidant enzymes such as superoxide dismutase. However, clinical trials involving gingko gave inconsistent results and from one study, involving more than 2800 participants, no reduction in the progression of AD was found (Vellas et al. 2012). In contrast, improvements both to cognitive functions and the neuropsychiatric symptoms of patients with $\mathrm{AD}$, who were treated with gingko EGB761, were reported. Positive clinical results and a satisfactory tolerance were also observed for patients with dementia, when administered with gingko EGB761. On the basis of experiments using animal models it was determined that the positive effect of gingko EGB761 is achieved via reduced apoptosis of the cells and a suppression of inflammation that is linked with cytokines such as tumor necrosis factor $\alpha$ and chemokine CCL-2 (Liu et al. 2015).

Uncaria rhynchophylla (Chotoko) is a Chinese plant used in traditional medicine (Xian et al. 2011) and a study was made of its protective effect against cognitive decline in mice, as induced by D-galactose (D-gal). The results demonstrated improvements in goal-orientated (for example, in searching for food) behavior, as assessed by an open-field test. Mice treated with $U$. rhynchophylla $(200,400 \mathrm{mg} /$ $\mathrm{kg}$ weight) showed inhibition of AChE which resulted in increased levels of acetylcholine and additionally, the levels of glutathione, one of the most effective intracellular antioxidants known, were found to be raised, which resulted in an elevated overall brain antioxidant status.

Lemon balm (Melissa officinalis) is a plant growing in Europe, Iran and Central Asia and contains compounds that belong to the terpene family. Melissa has been used throughout history to treat neurological disorders, including problems with memory and mood (Wightman 2017) and its relevant effect on the CNS is achieved via the action of monoterpenes and sesquiterpenes. In addition to their antioxidant effects, this group of compounds has a positive effect on neurons and toward the activation of the cholinergic system and upregulation of $\gamma$-aminobutyric acid-(GABA)-ergic neurons (Awad et al. 2009). From a clinical trial in which patients with mild to moderate $\mathrm{AD}$ were treated with lemon balm for 4 months, positive effects of $M$. officinalis on agitation were reported (Akhondzadeh et al. 2003). However, two alternative studies failed to find statistically significant positive results from the application of Melissa to AD patients, although it should be noted that in these investigations, the Melissa was administrated in the form of aromatherapy spray, so the exact dose received by patients was not known.

Curcumin is produced by Curcuma longa plants and it was demonstrated that its application could prevent deposition of $\mathrm{A} \beta$ in the brains of murine models for $\mathrm{AD}$ (Wang et al. 2009). In addition, it was found that an alleviated hyperphosphorylation of tau resulted from application of curcumin and that the substance also reduces the degree 
of oxidative stress by binding redox-active metals such as copper(II). Although a positive activity of curcumin has also been found toward the cholinergic system and on the overall antioxidant status of neurons (Tang and Taghibiglou 2017), the major barrier to the therapeutic use of curcumin is its low bioavailability and solubility. Thus, an intake of several grams of curcumin resulted in only nanomolar serum concentrations which are very low for a therapeutic effect to be achieved (Lao et al. 2006). Several formulations, such as curcumin-cyclodextrin have been tested and these were found to increase the solubility/bioavailability of curcumin by a factor of ten thousand. Another potential strategy that might improve the bioavailability of the material is based on the application of curcumin encapsulated in nanoparticles (nanocurcumin) (Bisht et al. 2007).

Panchagavya is an Ayurvedic medicine mixture consisting of five cow products and has been reported to improve cognitive performance, to attenuate seizures and suppress metal-induced oxidative stress in pentylenetetrazole-induced seizures in rats (Joshi et al. 2015).

Overall, it appears that herbs may provide an important source of new prospective drugs for the treatment of $\mathrm{AD}$ with a further advantage that the active components contained in herbs have relatively very mild side effects and may exhibit multitarget modes of action, to alleviate those pathological manifestations as are characteristic for $\mathrm{AD}$.

\section{Flavonoids}

Flavonoids are polyphenolic compounds that occur in plants and have significant antioxidant (radical-scavenging) and metal-chelating properties. There are six main subgroups of flavonoids: (1) flavanols, (2) flavones, (3) isoflavones, (4) flavanones, (5) flavanols and (6) anthocyanins (Williams et al. 2004). Although there is presently no direct association between neurological status and consumption of flavonoids, the beneficial effects of these materials appear to be related to their ROS scavenging properties, redox metal-chelating capacity and their interaction with intracellular neuronal and glial signaling pathways.

The antioxidant and metal-chelating properties of flavonoids along with their ability to interact with signaling pathways may render their therapeutic potential to prevent the onset and progression of AD. However, the prospective usefulness of flavonoids is mainly restricted to the prevention period or to the early stages of the development of the disease, although supplementation with flavonoids may result in improvements to cognitive performance, since metal-induced oxidative stress in $\mathrm{AD}$ affects mainly cognition and/or short-/long-term memory (Airoldi et al. 2018; Sureda et al. 2017; de Andrade Teles et al. 2018) Some biological roles for flavonoids are outlined in Fig. 4.

The biological activity of flavonoids is related to their molecular structural features of which the most important determinants of biological activity are the hydroxyl groups on the B ring and a $\mathrm{C} 2-\mathrm{C} 3$ double bond in the $\mathrm{C}$ ring (Fig. 5). These particular structural characteristics are all important determinants of the radical-scavenging (antioxidant) activity of flavonoids and due to their distinct structural characteristics, different flavonoids act differently in living cells according to their varying interactions with kinases or receptors.

Flavonoids are molecules that interact with various neuronal signaling pathways which may involve such protein kinase and lipid kinase signaling pathways as PI3K/Akt, mitogen-activated protein kinase (MAPK), NF-kappaB,

Fig. 4 Biological roles of flavonoids

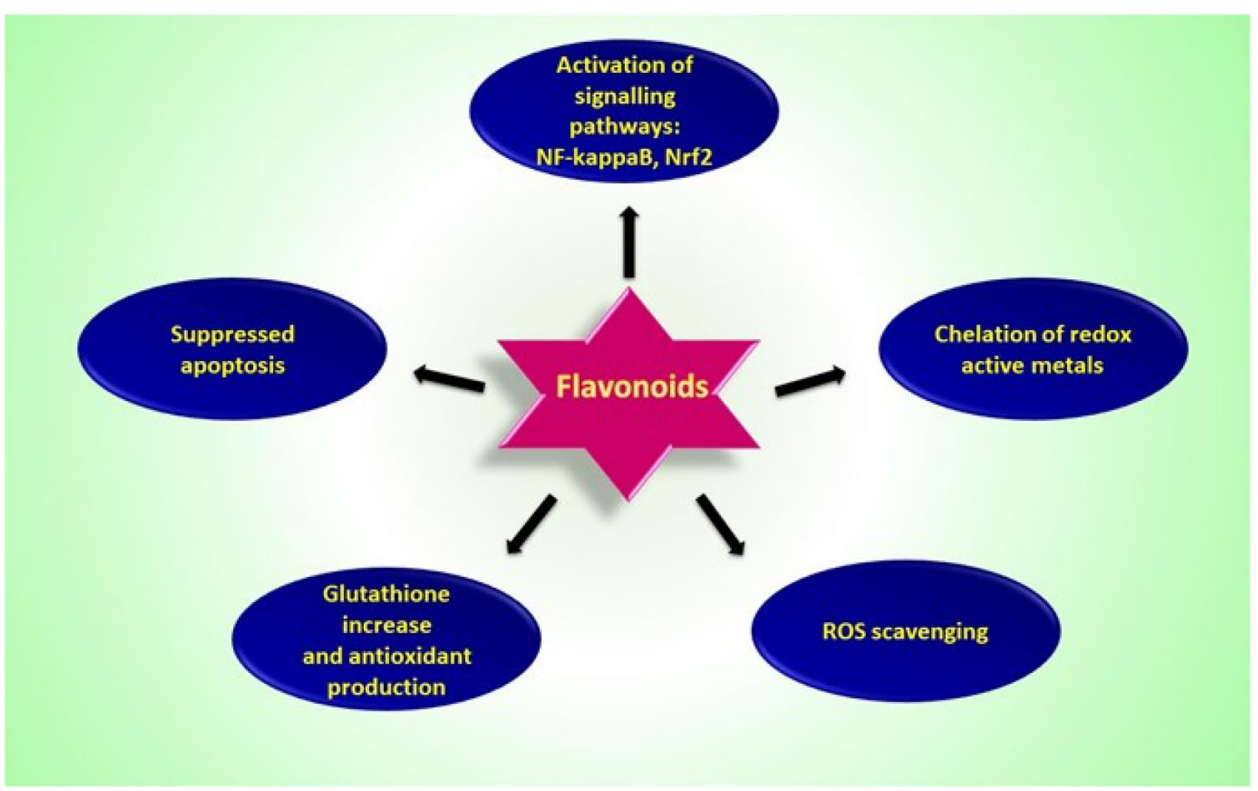


<smiles></smiles>

Quercetin<smiles>O=C(O[C@H]1Cc2c(O)cc(O)cc2O[C@@H]1c1cc(O)c(O)c(O)c1)c1cc(O)c(O)c(O)c1</smiles>

Epigallocatechin-3-gallate<smiles></smiles><smiles>O=c1c(O)c(-c2cc(O)c(O)c(O)c2)oc2cc(O)cc(O)c12</smiles>

Myricetin<smiles>Oc1cc(O)c2c(c1)O[C@H](c1ccc(O)c(O)c1)[C@H](O)C2</smiles><smiles>Oc1cc(O)c2c(c1)O[C@H](c1ccc(O)c(O)c1)[C@H](O)C2</smiles><smiles>O=c1c(O)c(-c2ccc(O)cc2O)oc2cc(O)cc(O)c12</smiles>

Morin<smiles>Oc1ccc(/C=C/c2cc(O)cc(O)c2)cc1</smiles>

Resveratrol

Fig. 5 Flavonoids with potential activity against Alzheimer's disease

tyrosine kinase, protein kinase $\mathrm{C}$ and other pathways (Spencer 2010). Upregulation or downregulation of signaling pathways significantly influences the functions of neurons by influencing the phosphorylation of target molecules.

Structurally similar flavonoids may activate different pathways. For example, while the flavonoid quercetin has been shown to inhibit Akt/PKB signaling pathways via inhibition of PI3-kinase activity, the structurally similar hesperetin has been found to activate Akt/PKB signaling and trigger prosurvival activity in neurons (Vauzour et al. 2007). In addition to its antioxidant activity, (-)epicatechin is able to modulate protein kinase signaling pathways and was demonstrated to stimulate a rapid, extracellular signal-regulated kinase (ERK)- and PI3-kinase-dependent increase in CREB phosphorylation, in addition to Akt phosphorylation, which showed bell-shaped concentration response characteristics (Schroeter et al. 2007). Some flavonoids are capable of disrupting fibrillization and can act as BACE-1 inhibitors, consequently resulting in suppression of $A \beta$ formation, but further studies are necessary to select the most potent flavonoids in this regard (Baptista et al. 2014).
Luteolin commonly occurs in parsley and celery and belongs to the group of flavone compounds. The neuroprotection of luteolin against cognitive decline and the accompanying mechanisms induced by $\mathrm{A} \beta$ peptide were studied in rats (Yu et al. 2015). On the basis of the results of animal behavior tests, it was revealed that luteolin was able to ameliorate $A \beta$-induced cognitive/memory impairments. Supplementation of rats with luteolin improved their antioxidant status by increasing the levels of acetylcholine, superoxide dismutase (SOD), glutathione peroxidase (GPX) and by simultaneously decreasing the levels of the oxidant malondialdehyde. Luteolin has been shown to support cell survival via increasing the $\mathrm{Bcl}-2 / \mathrm{Bax}$ ratio and thus this compound offers potential as a therapeutical agent to target both cholinergic and oxidative stress systems in AD.

Inhibition of glycogen synthase kinase 3 (GSK-3) may suppress pathological cleavage of APP. Luteolin has been shown to induce inhibition of GSK-3, which in turn decreased cleavage of APP by amyloidogenic $\gamma$-secretase (Rezai-Zadeh et al. 2009). Luteolin was also able to decrease the levels of soluble $A \beta$. A structurally similar flavonoid to 
luteolin, diosmin, has been found to suppress the pathological manifestations associated with $\mathrm{A} \beta$ in animal experiments.

Green, white and black teas contain the catechin, epigallocatechin-3-gallate (EGCG), which is frequently used in dietary supplements, due to its many health benefits. That EGCG has significant neuroprotective effects documented from a number of studies of cell lines and animal models (Mandel et al. 2008). EGCG has been shown to reduce A $\beta$ levels in the brain via the modulation of APP processing (Rezai-Zadeh et al. 2008; Gaudreault and Mousseau 2019) and it inhibits $A \beta$ aggregation in animal models via activation of $\alpha$-secretase and by disrupting unfolded peptide (Awasthi et al. 2016). On the basis of theoretical studies it was proposed that, in addition to electrostatic effects, van der Waals interactions between EGCG and A $\beta$ are important, and these appear to be responsible for the inhibitory activity of EGCG. EGCG not only reduces levels of $A \beta$, but can also lower levels of damaging ROS and ameliorate A $\beta$-induced mitochondrial dysfunction. It was found that ATP levels were increased by $75 \%$ in mitochondria isolated from various brain regions, such as cortex, striatum and hippocampus, due to the presence of EGCG (Dragicevic et al. 2011).

Among the most promising flavonoids that might be used for the protection of neurons against AD are myricetin, morin, rutin, quercetin, fisetin, kaempferol, apigenin and glycitein, since they have shown antiamyloidogenic and destabilizating effects toward A $\beta$ fibrils (Ono et al. 2003). The antiamyloidogenic and fibril-destabilization activities of some flavonoids, as studied in vitro, were found to be in the following order: myricetin $\sim$ morine $\sim$ quercetin $>$ kaempferol $>$ catechin, which can be rationalized on the basis of structural similarities/differences of these molecules. The molecules of myricetin, morine, quercetin and kaempferol lack chirality, and both catechol and $\gamma$-benzopyrone moieties are located in a single plane. In contrast, the catechin molecule possesses two chiral centers, so the two rings occupy different planes. The anti-AD properties of flavonoids are also markedly influenced by their substitution by hydroxyl groups and, thus, as the number of hydroxyl groups increases in the series of flavonoids (myricetin 6 , morin 5, quercetin 4 and kaempferol 4), their anti-AD activity also increases. From all of the above, it may be concluded that the antiamyloidogenic and fibril-destabilization properties of flavonoids are significantly influenced by the overall stereochemistry and number of hydroxyl groups in their molecules.

The optimal concentration of myricetin, morin, rutin and quercetin required for effective destabilization of $\mathrm{A} \beta$ fibrils has been found to be in the range of 0.1-1 $\mu \mathrm{M}$ (Ono et al. 2003). Molecular dynamics (MD) simulations revealed that destabilization of $A \beta$ fibrils by morin is achieved via its binding at the end groups of the fibrils, which thereby creates a barrier against the attachment of another peptide (Lemkul and Bevan 2010). In addition, morin interacts with the hydrophobic core of the $\mathrm{A} \beta$ and breaks the interaction between oppositely charged residues of the Asp23-Lys28 fragment, in addition to destabilizing the hydrogen bonding network of the backbone.

From clinical studies it was discovered that quercetin exerts potent neuroprotective effects in patients suffering from $\mathrm{AD}$ according to an improvement in learning and spatial memory tasks, as determined by the elevated plus maze test (Bhullar and Rupasinghe 2013). Accordingly, in our own research group, we have investigated the antioxidant effect of free quercetin and quercetin coordinated to copper ions with regard to the formation of ROS in the $\mathrm{Cu}$-catalyzed Fenton reaction and DNA damage (Jomova et al. 2017). Since the $\mathrm{Cu}$ (II)-quercetin (1:2) complex intercalates into DNA, a protective effect for quercetin via a ROS-scavenging mechanism has been confirmed only at higher stoichiometric ratios of quercetin relative to copper.

Some flavonoids are structurally homologous to the pharmacological modulators of ERK signaling and therefore their effect on the ERK pathways, via interactions with MAPK kinases MEK1 and MEK2 has been studied. It was found that activation of ERK can result in downstream activation of the cAMP response element-binding protein (CREB) which may upregulate neuroprotective pathways and synaptic plasticity and memory (Impey et al. 1998).

Catechins (e.g., EGCG) are the main components of green tea extract, and when senescence-accelerated mice were administered with green tea extracts for 6 months, it was shown that memory impairments were prevented by a suppressed formation of $A \beta$ increased activity of the CAMP-PKA/CREB pathway, and the upregulation of proteins related to synaptic plasticity. (Li et al. 2009).

Resveratrol is a naturally occurring phenol which is produced by several plants as a protective substance against injury (Gomes et al. 2018). Although resveratrol exists in two isomers, the pharmacological activity of the cis-isomer has not as yet been elucidated. Resveratrol is present both as a free substance and as $3 \beta$-glucoside resveratrol in grapes and wine. The solubility of resveratrol in water is rather low, as too is its bioavailability, since the substance rapidly degrades (Rege et al. 2014). To overcome the biological obstacles associated with resveratrol administration, various strategies have been proposed and tested, including encapsulation of resveratrol in liposomal formulations, the application of protein (carrier)-resveratrol complexes, the use of solid lipid nanoparticles and the formation of resveratrol-cyclodextrin complexes (Augustin et al. 2013).

The protective antioxidant/radical-scavenging properties of resveratrol against neuronal damage have been the subject of various studies (Wang et al. 2018). It was found that long-term supplementation with resveratrol in rats with streptozotocin-induced diabetes suppressed the formation of malondialdehyde and restored glutathione 
levels to normal (Sadi and Konat 2016). Resveratrol scavenges ROS either directly or indirectly via inhibition of pro-oxidative genes such as $\mathrm{NAD}(\mathrm{P}) \mathrm{H}$ and activation of antioxidant enzymes including SOD, catalase, GPX and thioredoxin (Carrizzo et al. 2013). On the basis of animal studies it was shown that in addition to its direct ROS scavenging activity, resveratrol suppresses the activity of enzymes involved in formation of ROS, such as iNOS, which is associated with the $A \beta$-induced peroxidation of lipids and downregulation of heme oxygenase-1 (HO-1) (Huang et al. 2011). Since resveratrol is able to interact with redox-active metal ions, such an interaction may prevent accumulation of iron or copper which might otherwise lead to copper and/or iron-induced formation of ROS and neuroinflammation. As discussed above, dysregulation of zinc is also linked with $\mathrm{AD}$, since accumulated zinc can indirectly promote ROS formation, mainly via displacing isostructural copper ions from copper-containing antioxidant enzymes. Resveratrol has not been shown to modulate zinc levels directly; however, the indirect and positive influence of resveratrol on zinc-related pathologies has been proven (Rege et al. 2014).

Resveratrol prevents the proinflammatory impact of $\mathrm{A} \beta$ on macrophages by inhibiting the activation of signal transducer and transcription (STAT) family proteins and of nuclear factor-kappaB, by interfering with IKK and IкB phosphorylation (Capiralla et al. 2012). An antiamyloidogenic effect of resveratrol is achieved by suppression of $A \beta$ formation/aggregation and by the destabilization of A $\beta$ fibrils (Rege et al. 2014). The long-term administration of resveratrol has been shown to be effective in protecting animals against $A \beta$-induced neuronal damage, increased expression of HO-1, cell death and lipid peroxidation.

Tannic acid is a plant polyphenol tannin containing a number of hydroxyl groups, which is found in green, black and white teas, bananas, beans, raspberries and other sources. Due to the number of hydroxyl groups present in its molecules, tannic acid can exert significant radical-scavenging/antioxidant, antiinflammatory and antibacterial effects and several in vivo and in vitro studies have demonstrated the neuroprotective effects of tannic acid against AD (Braidy et al. 2017). In addition to its redox metal-chelating and antioxidant properties, tannic acid is able to inhibit $\beta$-secretase (BACE1), which is responsible for the formation and deposition of the $\mathrm{A} \beta$ peptide, and it can also suppress aggregation of the principal component of intracellular neurobifrillary tangles (NFT), the $\tau$-peptide.

Investigations were made of the potential therapeutic activity of flavonoids against cognitive impairments using rodent models, which demonstrated that anthocyanin-fortified bilberry extracts could modulate the APP processing that was directly linked with $\mathrm{A} \beta$ production and ameliorate cognitive impairments (Vepsalainen et al. 2013).
From the above information, it can be concluded that supplementation of elderly people with polyphenols may provide protection against the incidence and progression of AD. While positive potential therapeutic effects are clearly documented from a number of different studies, it is likely to take some considerable time before this knowledge can be transferred to clinical applications for the prevention/treatment of neurodegenerative diseases such as AD. By extrapolating the doses used in animal studies to humans (with an average weight of ca $75 \mathrm{~kg}$ ), it appears that supplementation of about $3000 \mathrm{mg}$ to $15,000 \mathrm{mg}$ of a flavonoid per day is required; however, due to the fact that flavonoids undergo rapid metabolism and elimination or transformation, their bioavailability would appear to be a serious limitation. Hence, various formulations, for example, using nanocarriers, encapsulation matrixes and other means to increase the bioavailability of flavonoids for clinical applications, are necessary and it is hoped to prove successful in the near future.

Recently, it has been reported that corn silk contains many biologically active substances such as flavonoids, alkaloids, phytosterols, vitamins and other components (Li and Lapcik 2018; Ma et al. 2014; Hu and Deng 2011). Thus corn silk may be a valuable nutritional supplement to alleviate the symptoms of AD.

Metal complexes containing coordinated phenolic compounds (e.g., flavonoids) have been shown to be active against various cancer cells, such as leukemia cells, hepatocellular cells, cells of colon and rectum, cervical cells and other human cancer cells. Zn(II) and Mn(II) complexes with quercetin, $\mathrm{Ni}(\mathrm{II})$ complexes with rutin, Cd(II) complexes with morin and other metal-flavonoid complexes caused caspase activation and induction of apoptosis (Perron et al. 2011). Cytotoxicity of metal complexes was attributed predominantly to DNA intercalation mechanism of action. Intercalation mechanism has been substantiated by the insertion of a planar aromatic system of flavonoids between DNA base pairs. From the above follows that when selecting a suitable flavonoid for the treatment of $\mathrm{AD}$, possible prooxidant properties of the flavonoid must be taken into account.

\section{Antioxidants}

Melatonin (Fig. 6) was discovered in 1958 and is a hormone that regulates circadian rhythms. Melatonin's antioxidant properties were first described in 1993 by the group of Reiter (Tan et al. 1993). Although melatonin levels in the body decrease naturally, with age, $\mathrm{AD}$ patients have just half the level of melatonin as people without the disease. It has been found that supplementation of AD patients with melatonin alleviates both their sleep disorders and behavioral disturbances (sundowning) (Rosales-Corral et al.2012). 


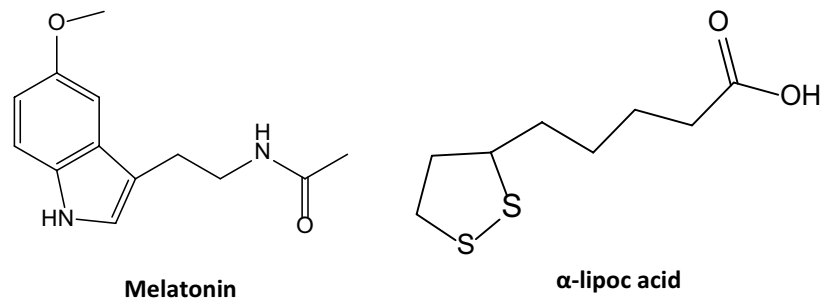

Fig. 6 Structures of melatonin and $\alpha$-lipoc acid

It has been proposed that melatonin may inhibit the enzyme $\beta$-secretase and simultaneously enhance the $\alpha$-secretase processing of $\beta$ APP. Since melatonin is a more efficient antioxidant than ascorbic acid and provides protection against metal-induced oxidative stress and also shows remarkable anti-neuroinflammatory properties, it is a promising potential therapeutic agent for the treatment of AD (Shukla et al. 2017). However, attention should be focused on optimizing both the required dose and the stage before the onset of the disease when melatonin should be administered.

An interesting link between ascorbic acid and $\mathrm{A} \beta$ has been reported (Dikalov et al. 2004). While neurotoxic forms of $\mathrm{A} \beta$ were found to stimulate $\mathrm{Cu}$-mediated oxidation of ascorbate anion $\left(\mathrm{AscH}^{-}\right)$to ascorbyl radical anion $\left(\mathrm{Asc}^{-}\right)$ (Eq. 9), the nontoxic form of $A \beta$ did not (Ryglewicz et al. 2002).

Oxidation of ascorbate anions by cupric ions reduces the latter to cuprous species (Eq. 10), which may catalyze the decomposition of hydrogen peroxide (Eq. 11) resulting in the formation of hydroxyl radicals. Reaction of cuprous species with molecular oxygen may regenerate cupric species and superoxide radical anions (Eq. 12). These reactions can be described as follows (see also Fig. 7):

$$
\begin{aligned}
& \mathrm{A} \beta-\mathrm{Cu}(\mathrm{II})+\mathrm{AscH}^{-} \leftrightarrow \mathrm{A} \beta-\mathrm{Cu}(\mathrm{I})+\mathrm{Asc}^{--}+\mathrm{H}^{+}, \\
& \mathrm{A} \beta-\mathrm{Cu}(\mathrm{II})+\mathrm{Asc}^{-} \leftrightarrow \mathrm{A} \beta-\mathrm{Cu}(\mathrm{I})+\mathrm{Asc}, \\
& \mathrm{A} \beta-\mathrm{Cu}(\mathrm{I})+\mathrm{H}_{2} \mathrm{O}_{2} \rightarrow \mathrm{A} \beta-\mathrm{Cu}(\mathrm{II})+\mathrm{OH}+\mathrm{OH}^{-} \text {(Fenton), } \\
& \mathrm{A} \beta-\mathrm{Cu}(\mathrm{I})+\mathrm{O}_{2} \leftrightarrow \mathrm{A} \beta-\mathrm{Cu}(\mathrm{II})+\mathrm{O}_{2}^{--} .
\end{aligned}
$$

A study has been made of the role of vitamin $E$ in the prevention of neurodegenerative disorders (Azzi et al. 2003), the results of which indicated that vitamin E supplementation may be of the greatest benefit if it is commenced well before the onset of the various diseases and applied for a prolonged period. In addition, the most effective strategy seems to be to consume vitamin $\mathrm{E}$ together with ascorbate (vitamin C), which has a capacity to regenerate vitamin $\mathrm{E}$ from its radical form (the tocopherol radical) (Fig. 1).

$\alpha$-Lipoic acid (Fig. 6) is a natural compound which is readily absorbed from the diet and reduced to its dithiol form, dihydrolipoic acid. Lipoic acid is soluble in both water and fat (Packer et al. 1995; Smith et al. 2004) and has been shown to confer physiological benefits to patients with AD. The beneficial properties of lipoic acid have been related to its antioxidant/radical-scavenging abilities and a stimulated formation of acetylcholine via activation of choline acetyltransferase. Lipoic acid is further able to chelate redoxactive metals and thus prevent the formation of ROS via the Fenton reaction and it also contributes to the formation of the reduced form of glutathione (GSH) (Packer et al. 1997).

From a study in which nine patients (age: $67 \pm 9$ years) with $\mathrm{AD}$ and dementias were supplemented daily with $600 \mathrm{mg}$ lipoic acid for a period of $337 \pm 80$ days (Maczurek et al. 2008), it was found that a stabilization of the decline of
Fig. 7 Amyloid- $\beta$-copper(II) complex and oxidation of ascorbate

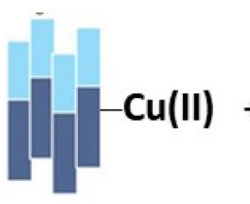

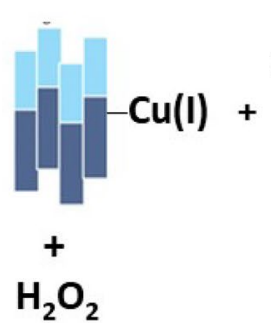

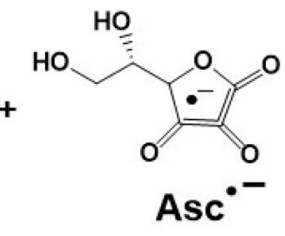

$\mathrm{H}_{2} \mathrm{O}_{2}$
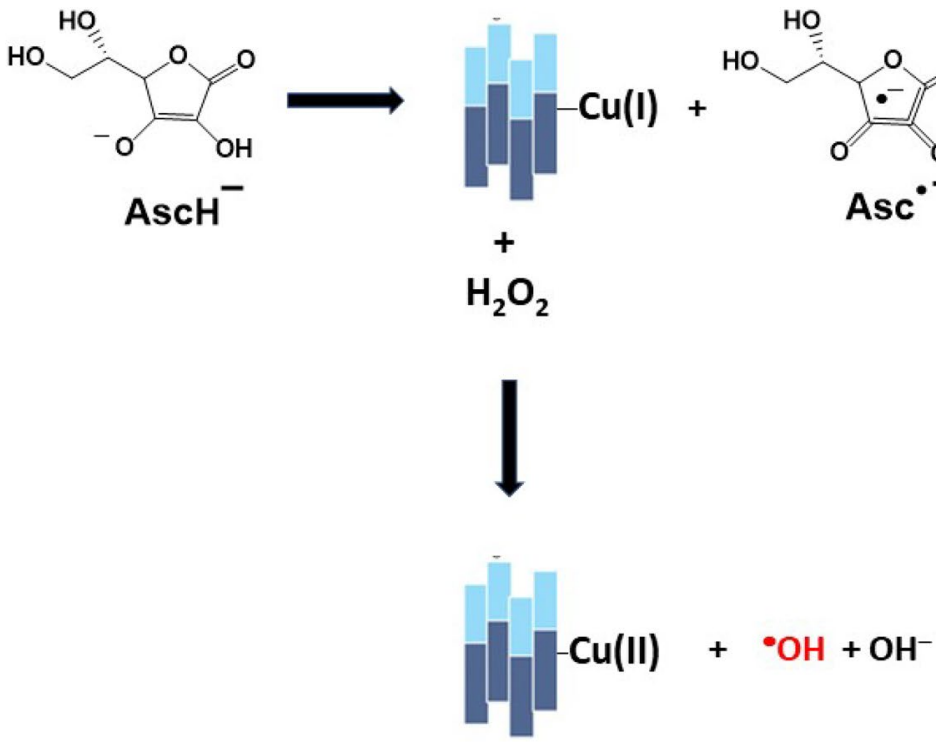
cognitive functions occurred, as demonstrated by the scores from two neuropsychological tests conducted over a period of almost 1 year. However, it has been pointed out that since lipoic acid is an effective chelator of redox-active metals, which may in turn lead to a depletion of metal-containing enzymes, its long-term use in the treatment of neurological diseases should be undertaken with caution (Suh et al. 2004).

\section{Conclusions}

$\mathrm{AD}$ is a multifactorial disease characterized by accumulation of the neurotoxic forms of $A \beta$ peptide, which are capable of forming amyloid plaques. $\mathrm{AD}$ is also linked to a deficiency in the neurotransmitter acetylcholine in brains that have been associated with altered activity of the enzyme AChE, which converts acetylcholine into choline and acetate. An imbalance in redox metal homeostasis, resulting in ROSinduced oxidative stress, appears to be an important factor in the pathogenesis of AD. The observed oxidative stress markers in the AD brain involve DNA oxidation products, hydroxyl radical adducts with DNA bases, lipid peroxides, RNS, advanced glycation end products and other markers (Hatanaka et al. 2015).

The current strategy of medicinal chemists for battling $\mathrm{AD}$ is based on the design and studies of multifunctional drugs that combine $\mathrm{A} \beta$ antiaggregation activity, $\mathrm{AChE}$ inhibitory activity, and antioxidant and metal-chelating activity. In addition, the application of herbal drugs, flavonoids and antioxidants has a great therapeutic potential.

The main focus of research in this field is on modifications of existing drugs that have specific biological activity, of which tacrine is probably the most frequently used due to its cholinesterase inhibitory activity and is applied for the design of multitarget-directed ligands. A number of hybrid compounds containing structural moieties derived from natural sources, such as flavonoids, alkaloids, coumarin and other molecules, have also been investigated for the treatment of $\mathrm{AD}$, the majority of which displayed improved antioxidant, metal-chelating and inhibitory activities toward AChE. Effective hybrid molecules include resveratrol, trolox and coumarin, in which the antioxidant moieties chelate redox metals and thus suppress metal-catalyzed formation of ROS (chelated metals have a lower catalytic activity than free metals) and/or directly scavenge ROS.

Many herbal drugs, such as huperzine A and B, ginseng, corilagen, curcumin and others are able to cross the BBB and exhibit therapeutic potential via the inhibition of AChE, chelation of redox-active metals, inhibition of the aggregation of $\mathrm{A} \beta$ and reduction of neuroinflammation.

Flavonoids not only act as antioxidants, but are also signaling molecules, and are able to slow down the progression of the disease and improve cognitive performance in patients suffering from AD. An important property is their ability to chelate redox metals and cause disruption of $\mathrm{A} \beta$ aggregation (Baptista et al. 2014). Several flavonoids have been reported with promising neuroprotective properties against cognitive dysfunction in AD. The flavonoid, quercetin, protects neurons against severe oxidative stress and attack by ROS via mild intercalation of its molecules into DNA, thus creating a protective barrier against stronger intercalators and/or attack by ROS.

Among the critical challenges that must be met in regard to the clinical use of antioxidants or flavonoids against $\mathrm{AD}$ are: to establish the ideal dose, to devise effective formulations to preserve bioavailability, and the most effective stage at which to administer the drug, so as to optimize the overall effectiveness of the antioxidant therapy. The key aim is to determine and optimize the age of the patient at which it is most effective to start the antioxidant therapy, to delay the onset of $\mathrm{AD}$ by at least 5 years. This would reduce the number of current sufferers of AD by one-half in less than 25 years. If the onset could be delayed by a decade, the current number of $\mathrm{AD}$ patients would be reduced by $80 \%$. Delaying the onset of the disease and/or alleviating the symptoms using multifunctional hybrid or single molecules is a critical goal in the battle against $\mathrm{AD}$.

Acknowledgements This work was supported by the Scientific Grant Agency (VEGA Project 1/0686/17) and Research and Development Support Agency (APVV-15-0079). I. A. and S. A. would like to thank the DSF program, King Saud University for support.

\section{Compliance with ethical standards}

Conflict of interest The authors declare that they have no conflict of interest.

Open Access This article is distributed under the terms of the Creative Commons Attribution 4.0 International License (http://creativeco mmons.org/licenses/by/4.0/), which permits unrestricted use, distribution, and reproduction in any medium, provided you give appropriate credit to the original author(s) and the source, provide a link to the Creative Commons license, and indicate if changes were made.

\section{References}

Airoldi C, La Ferla B, D’Orazio G, Ciaramelli C, Palmioli A (2018) Flavonoids in the treatment of Alzheimer's and other neurodegenerative diseases. Curr Med Chem 25(27):3228-3246. https:// doi.org/10.2174/0929867325666180209132125

Akhondzadeh S, Noroozian M, Mohammadi M, Ohadinia S, Jamshidi AH, Khani M (2003) Melissa officinalis extract in the treatment of patients with mild to moderate Alzheimer's disease: a double blind, randomised, placebo controlled trial. J Neurol Neurosurg Psychiatry 74(7):863-866. https://doi.org/10.1136/jnnp.74.7.863 
Ali FE, Separovic F, Barrow CJ, Cherny RA, Fraser F, Bush AI, Masters CL, Barnham KJ (2005) Methionine regulates copper/hydrogen peroxide oxidation products of Abeta. J Pept Sci 11:353-360. https://doi.org/10.1002/psc.626

Atwood CS, Moir RD, Huang XD et al (1998) Dramatic aggregation of Alzheimer abeta by $\mathrm{Cu}(\mathrm{II})$ is induced by conditions representing physiological acidosis. J Biol Chem 273:12817-12826. https:// doi.org/10.1074/jbc.273.21.12817

Augustin MA, Sanguansri L, Lockett T (2013) Nano- and micro-encapsulated systems for enhancing the delivery of resveratrol. Ann N Y Acad Sci 1290:107-112. https://doi.org/10.1111/nyas.12130

Awad R, Muhammad A, Durst T et al (2009) Bioassay-guided fractionation of Lemon balm (Melissa officinalis L.) using an in vitro measure of GABA transaminase activity. Phytother Res 23:10751081. https://doi.org/10.1002/ptr.2712

Awasthi M, Singh S, Pandey VP, Dwivedi UN (2016) Alzheimer's disease: an overview of amyloid beta dependent pathogenesis and its therapeutic implications along with in silico approaches emphasizing the role of natural products. J Neurol Sci 361:256-271. https://doi.org/10.1016/j.jns.2016.01.008

Azzi A, Gysin R, Kempna P, Ricciarelli R, Villacorta L, Visarius T, Zingg JM (2003) The role of a-tocopherol in preventing disease: from epidemiology to molecular events. Mol Asp Med 24:325336. https://doi.org/10.1016/S0098-2997(03)00028-1

Baptista FI, Henriques AG, Silva AM, Wiltfang J, da Cruz e Silva OA (2014) Flavonoids as therapeutic compounds targeting key proteins involved in Alzheimer's disease. ACS Chem Neurosci 5(2):83-92. https://doi.org/10.1021/cn400213r

Barnham KJ, Haeffner F, Ciccotosto GD et al (2004) Tyrosine gated electron transfer is key to the toxic mechanism of Alzheimer's disease beta-amyloid. FASEB J 18:1427-1429. https://doi. org/10.1096/fj.04-1890fje

Bhullar KS, Rupasinghe HP (2013) Polyphenols: multipotent therapeutic agents in neurodegenerative diseases. Oxid Med Cell Longev 2013:891748. https://doi.org/10.1155/2013/891748

Bisht S, Feldmann G, Soni S, Ravi R, Karikar C, Maitra A et al (2007) Polymeric nanoparticle-encapsulated curcumin ("nanocurcumin"): a novel strategy for human cancer therapy. J Nanobiotechnol 5(1):3. https://doi.org/10.1186/1477-3155-5-3

Block ML, Calderon-Garciduenas L (2009) Air pollution: mechanisms of neuroinflammation and CNS disease. Trends Neurosci 32:506-516. https://doi.org/10.1016/j.tins.2009.05.009

Braak H, Braak E (1991) Neuropathological staging of Alzheimerrelated changes. Acta Neuropathol 82:239-259

Braidy N, Jugder BE, Poljak A, Jayasena T, Nabavi SM, Sachdev P, Grant R (2017) Molecular targets of tannic acid in Alzheimer's disease. Curr Alzheimer Res 14(8):861-869. https://doi. org/10.2174/1567205014666170206163158

Bush AI (2003) The metallobiology of Alzheimer's disease. Trends Neurosci 26:207-214. https://doi.org/10.1016/S0166 -2236(03)00067-5

Bush AI, Curtain CC (2008) Twenty years of metallo-neurobiology: where to now? Eur Biophys J Biophys Lett 37:241-245. https:// doi.org/10.1007/s00249-007-0228-1

Butterfield DA, Halliwell B (2019) Oxidative stress, dysfunctional glucose metabolism and Alzheimer disease. Nat Rev Neurosci 20(3):148-160. https://doi.org/10.1038/s41583-019-0132-6

Capiralla H, Vingtdeux V, Zhao H, Sankowski R, Al-Abed Y, Davies P, Marambaud P (2012) Resveratrol mitigates lipopolysaccharide- and $\mathrm{A} \beta$-mediated microglial inflammation by inhibiting the TLR4/NF-кB/STAT signaling cascade. J Neurochem 120(3):461472. https://doi.org/10.1111/j.1471-4159.2011.07594.x

Carrizzo A, Forte M, Damato A, Trimarco V, Salzano F, Bartolo M et al (2013) Antioxidant effects of resveratrol in cardiovascular, cerebral and metabolic diseases. Food Chem Toxicol 61:215226. https://doi.org/10.1016/j.fct.2013.07.021
Cerpa WF, Barria MI, Chacon MA, Suazo M, Gonzalez M, Opazo C, Bush AI, Inestrosa NC (2004) The N-terminal copper-binding domain of the amyloid precursor protein protects against $\mathrm{Cu}_{2}$ ? Neurotoxicity in vivo. FASEB J 18:1701. https://doi.org/10.1096/ fj.03-1349fje

Ceschi MA, da Costa JS, Lopes JPB, Câmara VS, Campo LF et al (2016) Novel series of tacrine-tianeptine hybrids: synthesis, cholinesterase inhibitory activity, S100B secretion and a molecular modeling approach. Eur J Med Chem 121:758-772. https://doi. org/10.1016/j.ejmech.2016.06.025

Chafekar SM, Hoozemans JJM, Zwart R et al (2007) Abeta (1-42) induces mild endoplasmic reticulum stress in an aggregation state-dependent manner. Antioxid Redox Signal 9:2245-2254. https://doi.org/10.1089/ars.2007.1797

Chen K, Kazachkov M, Yu PH (2007) Effect of aldehydes derived from oxidative deamination and oxidative stress on beta-amyloid aggregation; pathological implications to Alzheimer's disease. J Neural Trans 114:835-839. https://doi.org/10.1007/s0070 2-007-0697-5

Chong CM, Zhou ZY, Naumovski VR, Cui GZ, Zhang LQ, Sa F, Hoi PM, Chan K, Lee SM (2013) Danshensu protects against 6-hydroxydopamine-induced damage of PC12 cells in vitro and dopaminergic neurons in zebrafish. Neurosci Lett 543:121-125. https://doi.org/10.1186/s13020-019-0242-0

Ciccotosto GD, Tew D, Curtain CC et al (2004) Enhanced toxicity and cellular binding of a modified amyloid beta peptide with a methionine to valine substitution. J Biol Chem 279:4252842534. https://doi.org/10.1074/jbc.M406465200

Coric B, Salloway S, van Dyck CH, Dubois B, Andreasen N, Brody M, Curtis C, Soininen H, Thein S, Shiovitz T, Pilcher G, Ferris S, Colby S, Kerselaers W, Dockens R, Soares H, Kaplita S, Luo F, Pachai C, Bracoud L, Mintun M, Grill JD, Marek K, Seibyl J, Cedarbaum JM, Albright C, Feldman HH, Berman RM (2015) Targeting prodromal alzheimer disease with avagacestat: a randomized clinical trial. JAMA Neurol 72:1324-1333. https://doi. org/10.1001/jamaneurol.2015.060

Cuajungco MP, Faget KY (2003) Zinc takes the center stage: its paradoxical role in Alzheimer's disease. Brain Res Rev 41:44-56. https://doi.org/10.1016/S0165-0173(02)00219-9

Cuajungco MP, Lees GJ (1998) Nitric oxide generators produce accumulation of chelatable zinc in hippocampal neuronal perikarya. Brain Res 799:118-129. https://doi.org/10.1016/s0006 -8993(98)00463-6

Cuajungco MP, Goldstein LE, Nunomura A et al (2000) Evidence that the beta-amyloid plaques of Alzheimer's disease represent the redox-silencing and entombment of A beta by zinc. J Biol Chem 275:19439-19442. https://doi.org/10.1074/jbc.C000165200

de Andrade Teles RB, Diniz TC, Costa Pinto TC, de Oliveira Júnior RG, Gama E Silva M, de Lavor ÉM, Fernandes AWC, de Oliveira AP, de Almeida Ribeiro FPR, da Silva AAM, Cavalcante TCF, Quintans Júnior LJ, da Silva Almeida JRG (2018) Flavonoids as therapeutic agents in Alzheimer's and Parkinson's diseases: a systematic review of preclinical evidences. Oxid Med Cell Longev 2018:7043213. https://doi.org/10.1155/2018/7043213

Deibel MA, Ehmann WD, Markesbery WD (1996) Copper, iron, and zinc imbalances in severely degenerated brain regions in Alzheimer's disease: possible relation to oxidative stress. J Neurol Sci 143:137-142. https://doi.org/10.1016/S0022-510X(96)00203-1

Deshpande A, Kawai H, Metherate R, Glabe CG, Busciglio J (2009) A role for synaptic zinc in activity-dependent Abeta oligomer formation and accumulation at excitatory synapses. J Neurosci 29:4004-4015. https://doi.org/10.1523/JNEUR OSCI.5980-08.2009

Devi L, Anandatheerthavarada HK (2010) Mitochondrial trafficking of APP and alpha synuclein: relevance to mitochondrial dysfunction 
in Alzheimer's and Parkinson's diseases. Biochim Biophys Acta 1802:11-19. https://doi.org/10.1016/j.bbadis.2009.07.007

Dikalov SI, Vitek MP, Mason RP (2004) Cupric-amyloid beta peptide complex stimulates oxidation of ascorbate and generation of hydroxyl radical. Free Radic Biol Med 36:340-347. https:// doi.org/10.1016/j.freeradbiomed.2003.11.004

Dong J, Shokes JE, Scott RA, Lynn DG (2006) Modulating amyloid self-assembly and fibril morphology with Zn(II). J Am Chem Soc 128:3540-3542. https://doi.org/10.1021/ja055973j

Doody RS, Raman R, Farlow M, Iwatsubo T, Vellas B, Joffe S, Kieburtz K, He F, Sun X, Thomas RG, Aisen PS, Siemers E, Sethuraman G, Mohs R (2013) A phase 3 trial of semagacestat for treatment of Alzheimer's disease. N Engl J Med 369:341350. https://doi.org/10.1056/NEJMoa1210951

Dragicevic N, Smith A, Lin X, Yuan F, Copes N, Delic V, Tan J, Cao C, Shytle RD, Bradshaw PC (2011) Green tea epigallocatechin3-gallate (EGCG) and other flavonoids reduce Alzheimer's amyloid-induced mitochondrial dysfunction. J Alzheimers Dis 26(3):507-521. https://doi.org/10.3233/JAD-2011-101629

Elsinghorst PW, Cieslik JS, Mohr K, Tränkle C, Gütschow M (2007) First gallamine-tacrine hybrid: design and characterization at cholinesterases and the M2 muscarinic receptor. J Med Chem 50(23):5685-5695. https://doi.org/10.1021/jm070859s

Fang F, Chen X, Huang T, Lue LF, Luddy JS, Yan SS (2012) Multifaced neuroprotective effects of ginsenoside Rg1 in an Alzheimer mouse model. Biochem Biophys Acta 1822:286-292. https://doi. org/10.3892/mmr.2016.5556

Garai K, Sahoo B, Kaushalya SK et al (2007) Zinc lowers amyloid-beta toxicity by selectively precipitating aggregation intermediates. Biochemistry 46:10655-10663. https://doi.org/10.1021/bi700 798 b

Gaudreault R, Mousseau N (2019) Mitigating Alzheimer's disease by natural polyphenols: a review. Curr Alzheimer Res 16:529-543. https://doi.org/10.2174/1567205016666190315093520

Geula C, Darvesh S (2004) Butyrylcholinesterase, cholinergic neurotransmission and the pathology of Alzheimer's disease. Drugs Today (Barc) 40:711-721. https://doi.org/10.1358/ dot.2004.40.8.850473

Girek M, Szymanski P (2019) Tacrine hybrids as multi-target-directed ligands in Alzheimer's disease: influence of chemical structures on biological activities. Chem Pap 73:269-289. https://doi. org/10.1007/s11696-018-0590-8

Gomes BAQ, Silva JPB, Romeiro CFR, Dos Santos SM, Rodrigues CA, Gonçalves PR, Sakai JT, Mendes PFS, Varela ELP, Monteiro MC (2018) Neuroprotective mechanisms of resveratrol in Alzheimer's disease: role of SIRT1. Oxid Med Cell Longev 2018:8152373. https://doi.org/10.1155/2018/8152373

Gong L, Li SL, Li H, Zhang L (2011) Ginsenoside Rg1 protects primary cultured rat hippocampal neurons from cell apoptosis induced by $\beta$-amyloid protein. Pharm Biol 49:501-507. https:// doi.org/10.3109/13880209.2010.521514

Haeffner F, Smith DG, Barnham KJ, Bush A (2005) Model studies of cholesterol and ascorbate oxidation by copper complexes: relevance to Alzheimer's disease beta-amyloid metallochemistry. J Inorg Biochem 99:2403-2422. https://doi.org/10.1016/j.jinor gbio.2005.09.011

Halliwell B (2001) Role of free radicals in the neurodegenerative diseases-therapeutic implications for antioxidant treatment. Drugs Aging 18:685-716. https://doi.org/10.2165/00002512-20011 8090-00004

Halliwell B, Gutteridge JMC (2007) Free radicals in biology and medicine, 4th edn. Oxford University Press, Oxford

Hamulakova S, Janovec L, Hrabinova M, Spilovska K, Korabecny J, Kristian P, Kuca K, Imrich J (2014) Synthesis and biological evaluation of novel tacrine derivatives and tacrine-coumarin hybrids as cholinesterase inhibitors. J Med Chem 2857(16):70737084. https://doi.org/10.1021/jm5008648

Hamulakova S, Poprac P, Jomova K, Brezova V, Lauro P, Drostinova L, Jun D, Sepsova V, Hrabinova M, Soukup O, Kristian P, Gazova Z, Bednarikova Z, Kuca K, Valko M (2016) Targeting copper(II)-induced oxidative stress and the acetylcholinesterase system in Alzheimer's disease using multifunctional tacrine-coumarin hybrid molecules. J Inorg Biochem 161:5262. https://doi.org/10.1016/j.jinorgbio.2016.05.001

Hardy J, Selkoe DJ (2002) Medicine-the amyloid hypothesis of Alzheimer's disease: progress and problems on the road to therapeutics. Science 297:353-356. https://doi.org/10.1126/ science. 1072994

Hatanaka H, Hanyu H, Fukasawa R, Hirao K, Shimizu S, Kanetaka H, Iwamoto T (2015) Differences in peripheral oxidative stress markers in Alzheimer's disease, vascular dementia and mixed dementia patients. Geriatr Gerontol Int 15(1):53-58. https:// doi.org/10.1111/ggi.12659

Herrup K (2015) The case for rejecting the amyloid cascade hypothesis. Nat Neurosci 18:794-799. https://doi.org/10.1038/nn.4017

Hiremathad A, Keri RS, Esteves AR, Cardoso SM, Chaves S, Santos MA (2018) Novel tacrine-hydroxyphenylbenzimidazole hybrids as potential multitarget drug candidates for Alzheimer's disease. Eur J Med Chem 148:255-267. https://doi. org/10.1016/j.ejmech.2018.02.023

Hu QI, Deng ZH (2011) Protective effects of flavonoids from corn silk on oxidative stress induced by exhaustive exercise in mice. Afr J Biotechnol 10:3163-3167. https://doi.org/10.5897/AJB10 .2671

Huang XD, Cuajungco MP, Atwood CS et al (1999) Cu(II) potentiation of Alzheimer abeta neurotoxicity-correlation with cell-free hydrogen peroxide production and metal reduction. J Biol Chem 274:37111-37116. https://doi.org/10.1074/jbc.274.52.37111

Huang TC, Lu KT, Wo YYP, Wu YJ, Yang YL (2011) Resveratrol protects rats from $A \beta$-induced neurotoxicity by the reduction of iNOS expression and lipid peroxidation. PLoS One 6:e29102. https://doi.org/10.1371/journal.pone.0029102

Huang XT, Qian ZM, He X, Gong Q, Wu KC, Jiang LR, Lu LN, Zhu ZJ, Zhang HY, Yung WH, Ke Y (2014) Reducing iron in the brain: a novel pharmacologic mechanism of huperzine $\mathrm{A}$ in the treatment of Alzheimer's disease. Neurobiol Aging 35:10451054. https://doi.org/10.1016/j.neurobiolaging.2013.11.004

Hung YH, Robb EL, Volitakis I et al (2009) Paradoxical condensation of copper with elevated beta-amyloid in lipid rafts under cellular copper deficiency conditions: implications for Alzheimer disease. J Biol Chem 284:21899-21907. https://doi.org/10.1074/ jbc.M109.019521

Hung YH, Bush AI, Cherny RA (2010) Copper in the brain and Alzheimer's disease. J Biol Inorg Chem 15:61-76. https://doi. org/10.1007/s00775-009-0600-y

Impey S, Smith DM, Obrietan K, Donahue R, Wade C, Storm DR (1998) Stimulation of cAMP response element (CRE)-mediated transcription during contextual learning. Nat Neurosci 1:595601. https://doi.org/10.1038/2830

Jalili-Baleh L, Babaei E, Abdpour S, Nasir Abbas Bukhari S, Foroumadi A, Ramazani A, Sharifzadeh M, Abdollahi M, Khoobi M (2018) A review on flavonoid-based scaffolds as multitarget-directed ligands (MTDLs) for Alzheimer's disease. Eur J Med Chem 152:570-589. https://doi.org/10.1016/j.ejmec h.2018.05.004

Jerabek J, Uliassi E, Guidotti L, Korábečný J, Soukup O, Sepsova V, Hrabinova M, Kuča K, Bartolini M, Peña-Altamira LE, Petralla S, Monti B, Roberti M, Bolognesi ML (2017) Tacrine-resveratrol fused hybrids as multi-target-directed ligands against Alzheimer's disease. Eur J Med Chem 127:250-262. https://doi. org/10.1016/j.ejmech.2016 
Jomova K, Lawson M, Drostinova L, Lauro P, Poprac P, Brezova V, Michalik M, Lukes V, Valko M (2017) Protective role of quercetin against copper(II)-induced oxidative stress: a spectroscopic, theoretical and DNA damage study. Food Chem Toxicol 110:340-350. https://doi.org/10.1016/j.fct.2017.10.042

Joshi R, Reeta KH, Sharma SK, Tripathi M, Gupta YK, Ghrita Panchagavya (2015) An Ayurvedic formulation attenuates seizures, cognitive impairment and oxidative stress in pentylenetetrazole induced seizures in rats. Indian J Exp Biol 53(7):446-451

Kim HJ, Kim P, Shin CY (2013) A comprehensive review of the therapeutic and pharmacological effects of ginseng and ginsenosides in central nervous system. J Ginseng Res 37:8-29. https://doi. org/10.5142/jgr.2013.37.8

Koch G, Di Lorenzo F, Bonnì S, Giacobbe V, Bozzali M, Caltagirone C, Martorana A (2014) Dopaminergic modulation of cortical plasticity in Alzheimer's disease patients. Neuropsychopharmacology 39:2654-2661. https://doi.org/10.1038/npp.2014.119

Korabecny J, Andrs M, Nepovimova E, Dolezal R, Babkova K, Horova A, Malinak D, Mezeiova E, Gorecki L, Sepsova V, Hrabinova M, Soukup O, Jun D, Kuca K (2015) 7-Methoxytacrine-p-anisidine hybrids as novel dual binding site acetylcholinesterase inhibitors for Alzheimer's disease treatment. Molecules 20(12):2208422101. https://doi.org/10.3390/molecules201219836

Kuca K, Juna D, Musilek K (2006) Structural requirements of acetylcholinesterase reactivators. Mini Rev Med Chem 6(3):269-277. https://doi.org/10.2174/138955706776073510

Kumar A, Singh A, Ekavali KC (2015) A review on Alzheimer's disease pathophysiology and its management: an update. Pharmacol Rep 67:195-203. https://doi.org/10.1016/j.pharep.2014.09.004

Kumar D, Ganeshpurkar A, Kumar D, Modi G, Gupta SK, Singh SK (2018) Secretase inhibitors for the treatment of Alzheimer's disease: long road ahead. Eur J Med Chem 148:436-452. https:// doi.org/10.1016/j.ejmech.2018.02.035

Lao CD, Ruffin MT, Normolle D, Heath DD, Murray SI, Bailey JM et al (2006) Dose escalation of a curcuminoid formulation. BMC Complement Altern Med 6(1):10. https://doi. org/10.1186/1472-6882-6-10

Lee B, Sur B, Park J, Kim SH, Kwon S, Yeom M, Shim I, Lee H, Hahm DH (2013) Ginsenoside rg3 alleviates lipopolysaccharideinduced learning and memory impairments by anti-inflammatory activity in rats. Biomol Ther (Seoul) 21(5):381-390. https://doi. org/10.4062/biomolther.2013.053

Lemkul JA, Bevan DR (2010) Destabilizing Alzheimer's A $\beta 42$ protofibrils with morin: mechanistic insights from molecular dynamics simulations. Biochemistry 49(18):3935-3946. https://doi. org/10.1021/bi1000855

Li P, Lapcik L (2018) The research of functional ingredients from corn silk. Chem Listy 112:93-97

Li Q, Zhao HF, Zhang ZF, Liu ZG, Pei XR, Wang JB, Li Y (2009) Long-term green tea catechin administration prevents spatial learning and memory impairment in senescence accelerated mouse prone- 8 mice by decreasing Abeta1 -42 oligomers and upregulating synaptic plasticity-related proteins in the hippocampus. Neuroscience 163:741-749. https://doi.org/10.1016/j.neuro science.2009.07.014

Li X, Deng Y, Zheng Z, Huang W, Chen L, Tong Q, Ming Y (2018) Corilagin, a promising medicinal herbal agent. Biomed Pharmacother 99:43-50. https://doi.org/10.1016/j.biopha.2018.01.030

Liu T, Jin H, Sun QR, Xu JH, Hu HT (2010) The neuroprotective effects of tanshinone IIA on $\beta$-amyloid-induced toxicity in rat cortical neurons. Neuropharmacology 59:595-604. https://doi. org/10.1016/j.neuropharm.2010.08.013

Liu X, Hao W, Qin Y, Decker Y, Wang X, Burkart M, Schotz K, Menger MD, Fassbender K, Liu Y (2015) Long-term treatment with Ginkgo biloba extract EGb 761 improves symptoms and pathology in a transgenic mouse model of Alzheimer's disease. Brain Behav Immun 46:121-123. https://doi.org/10.1016/j. bbi.2015.01.011

Lovejoy DB, Richardson D (2003) Iron chelators as anti-neoplastic agents: current developments and promise of the PIH class of chelators. Curr Med Chem 10:1035-1049. https://doi. org/10.2174/0929867033457557

Lu J, Song HP, Li P, Zhou P, Dong X, Chen J (2015) Screening of direct thrombin inhibitors from Radix Salviae miltiorrhizae by a peak fractionation approach. J Pharm Biomed 109:85-90. https ://doi.org/10.1016/j.jpba.2015.02.020

Ma X, Wu L, Zhao H, Zeng D, Bai S (2014) Research progress of the Chinese medicine and herb prevention effect of the Alzheimer's disease. Hunan Chin Tradit Med 11:177-179

MacLeod R, Hillert EK, Cameron RT, Baillie GS (2015) The role and therapeutic targeting of $\alpha, \beta$ - and $\gamma$-secretase in Alzheimer's disease. Fut Sci OA 1(3):FSO11. https://doi.org/10.4155/fso.15.9

Maczurek A, Hagera K, Kenkliesa K et al (2008) Lipoic acid as an anti-inflammatory and neuroprotective treatment for Alzheimer's disease. Adv Drug Deliv Rev 60:1463-1470. https://doi. org/10.1016/j.addr.2008.04.015

Mandel SA, Amit T, Kalfon L, Reznichenko L, Weinreb O, Youdim MB (2008) Cell signaling pathways and iron chelation in the neurorestorative activity of green tea polyphenols: special reference to epigallocatechin gallate (EGCG). J Alzheimer's Dis $15(2): 211-222$

Maret W (2019) The redox biology of redox-inert zinc ions. Free Radic Biol Med 6(134):311-326. https://doi.org/10.1016/j.freeradbio med.2019.01.006

Martorana A, Koch G (2014) Is dopamine involved in Alzheimier's disease? Front Aging Neurosci 6:252. https://doi.org/10.3389/ fnagi.2014.00252

Matés JM, Pérez-Gómez C, Nunez de Castro I (1999) Antioxidant enzymes and human diseases. Clin Biochem 32(8):595-603. https://doi.org/10.1016/S0009-9120(99)00075-2

Mehta M, Adem A, Sabbagh M (2012) New acetylcholinesterase inhibitors for Alzheimer's disease. Int J Alzheimer Dis. https:// doi.org/10.1155/2012/728983 (Art 728983)

Misik J, Korabecny J, Nepovimova E, Cabelova P, Kassa J (2015) The effects of novel 7-MEOTA-donepezil like hybrids and $\mathrm{N}$-alkylated tacrine analogues in the treatment of quinuclidinyl benzilate-induced behavioural deficits in rats performing the multiple T-maze test. Biomed Pap Med Fac Univ Palacky Olomouc Czech Repub 159(4):547-553. https://doi.org/10.5507/ bp. 2015.006

Nepovimova E, Korabecny J, Dolezal R, Babkova K, Ondrejicek A, Jun D, Sepsova V, Horova A, Hrabinova M, Soukup O, Bukum N, Jost P, Muckova L, Kassa J, Malinak D, Andrs M, Kuca K (2015) Tacrine-trolox hybrids: a novel class of centrally active, nonhepatotoxic multi-target-directed ligands exerting anticholinesterase and antioxidant activities with low in vivo toxicity. J Med Chem 58(22):8985-9003. https://doi.org/10.1021/acs.jmedc hem.5b01325

Ong WY, Halliwell B (2004) Iron, atherosclerosis, and neurodegeneration-a key role for cholesterol in promoting iron-dependent oxidative damage? Ann N Y Acad Sci 1012:51-64. https://doi. org/10.1196/annals.1306.005

Ono K, Yoshiike Y, Takashima A, Hasegawa K, Naiki H, Yamada M (2003) Potent anti-amyloidogenic and fibril-destabilizing effects of polyphenols in vitro: implications for the prevention and therapeutics of Alzheimer's disease. J Neurochem 87:172-181. https ://doi.org/10.1046/j.1471-4159.2003.01976.x

Orhan G, Orhan I, Oztekin-Subutay N, Ak F, Sener B (2009) Contemporary anticholinesterase pharmaceuticals of natural origin and their synthetic analogues for the treatment of Alzheimer's 
disease. Recent Pat CNS Drug Discov 4(1):43-51. https://doi. org/10.2174/157488909787002582

Packer L, Witt EH, Tritschler HJ (1995) Alfa-lipoic acid as a biological antioxidant. Free Radic Biol Med 19:227-250. https://doi. org/10.1016/0891-5849(95)00017-R

Packer L, Tritschler HJ, Wessel K (1997) Neuroprotection by the metabolic antioxidant alpha-lipoic acid. Free Radic Biol Med 22:359-378. https://doi.org/10.1016/S0891-5849(96)00269-9

Pereira DM, Ferreres F, Oliveira JM, Gaspar L, Faria J, Valentão P et al (2010) Pharmacological effects of Catharanthus roseus root alkaloids in acetylcholinesterase inhibition and cholinergic neurotransmission. Phytomedicine 17:646-652. https://doi. org/10.1016/j.phymed.2009.10.008

Perron NR, Garcia CR, Pizon JR, Chaur MN, Brumaghin JL (2011) Antioxidant and prooxidants effects of polyphenol compounds on copper mediated DNA damage. J Inorg Biochem 105:745753. https://doi.org/10.1016/j.jinorgbio.2011.02.009

Pimplikar SW (2009) Reassessing the amyloid cascade hypothesis of Alzheimer's disease. Int J Biochem Cell Biol 41:1261-1268. https://doi.org/10.1016/j.biocel.2008.12.015

Pogocki D (2003) Alzheimer's beta-amyloid peptide as a source of neurotoxic free radicals: the role of structural effects. Acta Neurobiol Exp 63:131-145

Poprac P, Jomova K, Simunkova M, Kollar V, Rhodes CJ, Valko $M$ (2017) Targeting free radicals in oxidative stress-related human diseases. Trends Pharmacol Sci 38(7):592-607. https ://doi.org/10.1016/j.tips.2017.04.005

Prati F, Cavalli A, Bolognesi ML (2016) Navigating the chemical space of multitarget-directed ligands: from hybrids to fragments in Alzheimer's disease. Molecules 21:466. https://doi. org/10.3390/molecules21040466

Premkumar DR, Smith MA, Richey PL, Petersen RB, Castellani R, Kutty RK, Wiggert B, Perry G, Kalaria RN (1995) Induction of heme oxygenase-1 messenger-RNA and protein in neocortex and cerebral vessels in Alzheimer's-disease. J Neurochem 65:1399-1402. https://doi.org/10.104 6/j.1471-4159.1995.65031399.x

Rajendran R, Minqin R, Ynsa MD, Casadesus G, Smith MA, Perry G, Halliwell B, Watt F (2009) A novel approach to the identification and quantitative elemental analysis of amyloid deposits insights into the pathology of Alzheimer's disease. Biochem Biophys Res Commun 382(1):91-95. https://doi.org/10.1016/j. bbrc.2009.02.136

Rege SD, Geetha T, Griffin GD, Broderick TL, Babu JR (2014) Neuroprotective effects of resveratrol in Alzheimer disease pathology. Front Aging Neurosc 6:218. https://doi.org/10.3389/fnagi .2014 .00218

Reynolds MR, Berry RW, Binder LI (2005) Site-specific nitration differentially influences tau assembly in vitro. Biochemistry 44:13997-14009. https://doi.org/10.1021/bi051028w

Rezai-Zadeh K, Arendash GW, Hou H, Fernandez F, Jensen M, Runfeldt M, Shytle RD, Tan J (2008) Green tea epigallocatechin3-gallate (EGCG) reduces beta-amyloid mediated cognitive impairment and modulates tau pathology in Alzheimer transgenic mice. Brain Res 1214:177-187. https://doi.org/10.1016/j. brainres.2008.02.107

Rezai-Zadeh K, Shytle RD, Bai Y, Tian J, Hou H, Mori T, Zeng J, Obregon D, Town T, Tan J (2009) Flavonoid-mediated presenilin-1 phosphorylation reduces Alzheimer's disease $\beta$-amyloid production. J Cell Mol Med 13:574-588. https://doi.org/10.111 1/j.1582-4934.2008.00344.x

Roberts BR, Ryan TM, Bush AI, Masters CL, Duce JA (2012) The role of metallobiology and amyloid-beta peptides in Alzheimer's disease. J Neurochem 120(1):149-166. https://doi.org/10.111 $1 / \mathrm{j} .1471-4159.2011 .07500 . \mathrm{x}$
Rodríguez-Franco MI, Fernández-Bachiller MI, Pérez C, Hernández-Ledesma B, Bartolomé B (2006) Novel tacrine-melatonin hybrids as dual-acting drugs for Alzheimer disease, with improved acetylcholinesterase inhibitory and antioxidant properties. J Med Chem 49(2):459-462. https://doi.org/10.1021/jm050 $746 \mathrm{~d}$

Romero A, Cacabelos R, Oset-Gasque MJ, Samadi A, Marco-Contelles J (2013) Novel tacrine-related drugs as potential candidates for the treatment of Alzheimer's disease. Bioorg Med Chem Lett 23(7):1916-1922. https://doi.org/10.1016/j.bmcl.2013.02.017

Rosales-Corral SA, Acuña-Castroviejo D, Coto-Montes A, Boga JA, Manchester LC, Fuentes-Broto L, Korkmaz A, Ma S, Tan DX, Reiter RJ (2012) Alzheimer's disease: pathological mechanisms and the beneficial role of melatonin. J Pineal Res 52(2):167-202. https://doi.org/10.1111/j.1600-079X.2011.00937.x

Ryglewicz D, Rodo M, Kunicki PK, Bednarska-Makaruk M et al (2002) Plasma antioxidant activity and vascular dementia. J Neurol Sci 203-204:195-197. https://doi.org/10.1159/000091710

Sadi G, Konat D (2016) Resveratrol regulates oxidative biomarkers and antioxidant enzymes in the brain of streptozotocin-induced diabetic rats. Pharm Biol 54(7):1-8. https://doi.org/10.3109/13880 209.2015.1056311

Sayre LM, Smith MA, Perry G (2001) Chemistry and biochemistry of oxidative stress in neurodegenerative disease. Curr Med Chem 8:721-738. https://doi.org/10.2174/0929867013372922

Schedin-Weiss S, Winblad B, Tjernberg LO (2014) The role of protein glycosylation in Alzheimer disease. FEBS J 281(1):46-62. https ://doi.org/10.1111/febs. 12590

Schroeter H, Bahia P, Spencer JP, Sheppard O, Rattray M, Cadenas E, Rice-Evans C, Williams RJ (2007) (-)Epicatechin stimulates ERK-dependent cyclic AMP response element activity and upregulates GluR2 in cortical neurons. J Neurochem 101:15961606. https://doi.org/10.1111/j.1471-4159.2006.04434.x

Selkoe DJ (2001) Alzheimer's disease: genes, proteins, and therapy. Physiol Rev 81:741-766. https://doi.org/10.1152/physr ev.2001.81.2.741

Shi Y, Zhang H, Wang W, Yan Fu, Xia Y, Tang X, Bai D, He X (2009) Novel 16-substituted bifunctional derivatives of huperzine $\mathrm{B}$ : multifunctional cholinesterase inhibitors. Acta Pharmacol Sin 30:1195-1203. https://doi.org/10.1038/aps.2009.91

Shi C, Liu J, Wu F, Yew DT (2010) Ginkgo biloba extract in Alzheimer's disease: from action mechanisms to medical practice. Int J Mol Sci 11:107-123. https://doi.org/10.3390/ijms11010107

Shukla M, Govitrapong P, Boontem P, Reiter RJ, Satayavivad J (2017) Mechanisms of melatonin in alleviating Alzheimer's disease. Curr Neuropharmacol 15:1010-1031. https://doi.org/10.3390/ ijms140714575

Singh N, Agrawal M, Dore S (2013) Neuroprotective properties and mechanisms of resveratrol in in vitro and in vivo experimental cerebral stroke models. ACS Chem Neurosci 4:1151-1162. https ://doi.org/10.1021/cn400094w

Smith AR, Shenvi SV, Widlansky M, Suh JH, Hagen TM (2004) Lipoic acid as a potential therapy for chronic diseases associated with oxidative stress. Curr Med Chem 11:1135-1146. https://doi. org/10.2174/0929867043365387

Smith DP, Smith DG, Curtain CC et al (2006) Copper-mediated amyloid-beta toxicity is associated with an intermolecular histidine bridge. J Biol Chem 281:15145-15154. https://doi.org/10.1074/ jbc.M600417200

Spencer JP (2010) Beyond antioxidants: the cellular and molecular interactions of flavonoids and how these underpin their actions on the brain. Proc Nutr Soc 69:244-260. https://doi.org/10.1017/ S0029665110000054

Spilovska K, Korabecny J, Kral J, Horova A, Musilek K, Soukup O, Drtinova L, Gazova Z, Siposova K, Kuca K (2013) 7-Methoxytacrine-adamantylamine heterodimers as cholinesterase inhibitors 
in Alzheimer's disease treatment-synthesis, biological evaluation and molecular modeling studies. Molecules 18(2):2397-2418. https://doi.org/10.3390/molecules 18022397

Spilovska K, Korabecny J, Sepsova V, Jun D, Hrabinova M, Jost P, Muckova L, Soukup O, Janockova J, Kucera T, Dolezal R, Mezeiova E, Kaping D, Kuca K (2017) Novel tacrine-scutellarin hybrids as multipotent anti-Alzheimer's agents: design, synthesis and biological evaluation. Molecules. https://doi.org/10.3390/ molecules22061006

Spuch C, Antequera D, Isabel Fernandez-Bachiller M, Isabel Rodríguez-Franco M, Carro E (2010) A new tacrine-melatonin hybrid reduces amyloid burden and behavioral deficits in a mouse model of Alzheimer's disease. Neurotox Res 17(4):421-431. https://doi.org/10.1007/s12640-009-9121-2

Suh JH, Zhu BZ, De Szoeke E, Frei B, Hagen TM (2004) Dihydrolipoic acid lowers the redox activity of transition metal ions but does not remove them from the active site of enzymes. Redox Rep 9:57-61. https://doi.org/10.1179/135100004225003923

Sureda A, Xavier C, Tejada S (2017) Neuroprotective effects of flavonoid compounds on neuronal death associated to Alzheimer's disease. Curr Med Chem. https://doi.org/10.2174/0929867325 666171226103237

Tan DX, Chen LD, Poeggeler B, Manchester LC, Reiter RJ (1993) Melatonin: a potent, endogenous hydroxyl radical scavenger. Endocr J 1:57-60. https://doi.org/10.1111/j.1749-6632.1994.tb21831.x

Tang M, Taghibiglou C (2017) The mechanisms of action of curcumin in Alzheimer's disease. J Alzheimers Dis 58(4):1003-1016. https ://doi.org/10.3233/JAD-170188

Tillement JP, Lecanu L, Papadopoulos V (2010) Amyloidosis and neurodegenerative diseases: current treatments and new pharmacological options. Pharmacology 85:1-17. https://doi. org/10.1159/000259044

Tumiatti V, Minarini A, Bolognesi ML, Milelli A, Rosini M, Melchiorre C (2010) Tacrine derivatives and Alzheimer's disease. Curr Med Chem 17(17):1825-1838. https://doi.org/10.2174/0929867107 91111206

Valko M, Izakovic M, Mazur M, Rhodes CJ, Telser J (2004) Role of oxygen radicals in DNA damage and cancer incidence. Mol Cell Biochem 266:37-56. https://doi.org/10.1023/B:MCBI.00000 49134.69131.89

Valko M, Morris H, Cronin MTD (2005) Metals, toxicity and oxidative stress. Curr Med Chem 12(10):1161-1208. https://doi. org/10.2174/0929867053764635

Valko M, Rhodes CJ, Moncol J, Izakovic M, Mazur M (2006) Free radicals, metals and antioxidants in oxidative stress-induced cancer. Chem Biol Interact 160(1):1-40. https://doi.org/10.1016/j. cbi.2005.12.009

Valko M, Jomova K, Rhodes CJ, Kuca K, Musilek K (2016) Redoxand non-redox-metal-induced formation of free radicals and their role in human disease. Arch Toxicol 90(1):1-37. https:// doi.org/10.1007/s00204-015-1579-5

Varadarajan S, Yatin S, Aksenova M, Butterfield DA (2000) Review: Alzheimer's amyloid beta-peptide-associated free radical oxidative stress and neurotoxicity. J Struct Biol 130:184-208. https:// doi.org/10.1006/jsbi.2000.4274

Vauzour D, Vafeiadou K, Rice-Evans C, Williams RJ, Spencer JP (2007) Activation of pro-survival Akt and ERK1/2 signalling pathways underlie the anti-apoptotic effects of flavanones in cortical neurons. J Neurochem 103:1355-1367. https://doi.org/10.1 111/j.1471-4159.2007.04841.x

Vellas B, Coley N, Ousset PJ, Berrut G, Dartigues JF, Dubois B, Grandjean H, Pasquier F, Piette F, Robert P, Touchon J, Garnier P, Mathiex-Fortunet H, Andrieu S (2012) Long-term use of standardised ginkgo biloba extract for the prevention of Alzheimer's disease (GuidAge): a randomised placebo-controlled trial. Lancet Neurol 11:851-859. https://doi.org/10.1016/S1474 $-4422(12) 70206-5$

Vepsalainen S, Koivisto H, Pekkarinen E, Makinen P, Dobson G, McDougall GJ, Stewart D, Haapasalo A, Karjalainen RO, Tanila H, Hiltunen M (2013) Anthocyanin-enriched bilberry and blackcurrant extracts modulate amyloid precursor protein processing and alleviate behavioral abnormalities in the APP/PS1 mouse model of Alzheimer's disease. J Nutr Biochem 24:360-370. https ://doi.org/10.1016/j.jnutbio.2012.07.006

Wang YJ, Thomas P, Zhong JH, Bi FF, Kosaraju S, Pollard A, Fenech M, Zhou XF (2009) Consumption of grape seed extract prevents amyloid-beta deposition and attenuates inflammation in brain of an Alzheimer's disease mouse. Neurotox Res 15:3-14. https:// doi.org/10.1007/s12640-009-9000-x

Wang ZY, Liu JG, Yang HM (2016) Pharmacological effects of active components of Chinese herbal medicine in the treatment of Alzheimer's disease: a review. Am J Chin Med 33:1-17. https://doi. org/10.1142/S0192415X16500853

Wang H, Jiang T, Li W, Gao N, Zhang T (2018) Resveratrol attenuates oxidative damage through activating mitophagy in an in vitro model of Alzheimer's disease. Toxicol Lett 282:100-108. https ://doi.org/10.1016/j.toxlet.2017.10.021

Weng YS, Wang HF, Pai PY, Jong GP, Lai CH, Chung LC, Hsieh DJ, HsuanDay C, Kuo WW, Huang CY (2015) Tanshinone IIA prevents Leu27IGF-II-induced cardiomyocyte hypertrophy mediated by estrogen receptor and subsequent Akt Activation. Am J Chin Med 43:1567-1591. https://doi.org/10.1142/S0192415X1 5500895

Wightman EL (2017) Potential benefits of phytochemicals against Alzheimer's disease. Proc Nutr Soc 76(2):106-112. https://doi. org/10.1017/S0029665116002962

Williams RJ, Spencer JP, Rice-Evans C (2004) Flavonoids: antioxidants or signalling molecules? Free Radic Biol Med 36(7):838-849. https://doi.org/10.1016/j.freeradbiomed.2004.01.001

Wong KK, Ngo JC, Liu S, Lin HQ, Hu C, Shaw PC, Wan DC (2010) Interaction study of two diterpenes, cryptotanshinone and dihydrotanshinone, to human acetylcholinesterase and butyrylcholinesterase by molecular docking and kinetic analysis. Chem Biol Interact 187:335-339. https://doi.org/10.1016/j.cbi.2010.03.026

Xian YF, Lin ZX, Mao QQ, Ip SP, Che CT (2011) Uncaria rhynchophylla ameliorates cognitive deficits induced by D-galactose in mice. Planta Med 77(18):1977-1983. https://doi. org/10.1055/s-0031-1280125

Xie SS, Wang XB, Li JY, Yang L, Kong LY (2013) Design, synthesis and evaluation of novel tacrine-coumarin hybrids as multifunctional cholinesterase inhibitors against Alzheimer's disease. Eur J Med Chem 64:540-553. https://doi.org/10.1016/j.ejmec h.2013.03.051

Xie SS, Wang X, Jiang N, Yu W, Wang KD, Lan JS, Li ZR, Kong LY (2015) Multi-target tacrine-coumarin hybrids: cholinesterase and monoamine oxidase B inhibition properties against Alzheimer's disease. Eur J Med Chem 95:153-165. https://doi.org/10.1016/j. ejmech.2015.03.040

Xiuli W, Wei G, Mao S (2015) Pharmacokinetic investigation on interaction between hydrophilic lithospermic acid B and lipophilic tanshinone IIA in rats: an experimental study. J Tradit Chin Med 35:206-210

Youn K, Lee S, Jeong WS, Ho CT, Jun M (2016) Protective role of corilagin on A $\beta 25$-35-induced neurotoxicity: suppression of NF-кB signaling pathway. J Med Food 19(10):901-911. https:// doi.org/10.1089/jmf.2016.3714

Yu TX, Zhang P, Guan Y, Zhen MQ (2015) Protective effects of luteolin against cognitive impairment induced by infusion of $A \beta$ peptide in rats. Int J Clin Exp Pathol 8(6):6740-6747 
Zhu J, Yang H, Chen Y, Lin H, Li Q, Mo J, Bian Y, Pei Y, Sun H (2018) Synthesis, pharmacology and molecular docking of multifunctional tacrine-ferulic acid hybrids as cholinesterase inhibitors against Alzheimer's disease. J Enzyme Inhib Med Chem 33(1):496-506. https://doi.org/10.1080/14756366.2018.1430691
Publisher's Note Springer Nature remains neutral with regard to jurisdictional claims in published maps and institutional affiliations.

\section{Affiliations}

\section{Miriama Simunkova ${ }^{1} \cdot$ Saleh H. Alwasel ${ }^{2} \cdot$ Ibrahim M. Alhazza $^{2} \cdot$ Klaudia Jomova $^{3} \cdot$ Vojtech Kollar $^{4} \cdot$ Miroslav Rusko $^{5}$. Marian Valko ${ }^{1,2}$ (i)}

1 Faculty Chemical and Food Technology, Slovak University of Technology, 81237 Bratislava, Slovakia

2 Zoology Department, College of Science, King Saud University, Riyadh, Saudi Arabia

3 Department of Chemistry, Constantine the Philosopher University in Nitra, 94974 Nitra, Slovakia
4 School of Economics and Management in Public Administration in Bratislava, Furdekova 16, 85104 Bratislava, Slovakia

5 Faculty of Material Science and Technology, Slovak University of Technology, 91724 Trnava, Slovakia 